\title{
The Bosch Process - Performance of a Developmental Reactor and Experimental Evaluation of Alternative Catalysts
}

\author{
Morgan B. Abney ${ }^{1}$ and J. Matthew Mansell ${ }^{2}$ \\ NASA Marshall Space Flight Center, Huntsville, AL, 35812
}

\begin{abstract}
Bosch-based reactors have been in development at NASA since the 1960's. Traditional operation involves the reduction of carbon dioxide with hydrogen over a steel wool catalyst to produce water and solid carbon. While the system is capable of completely closing the loop on oxygen and hydrogen for Atmosphere Revitalization, steel wool requires a reaction temperature of $650^{\circ} \mathrm{C}$ or higher for optimum performance. The single pass efficiency of the reaction over steel wool has been shown to be less than $10 \%$ resulting in a high recycle stream. Finally, the formation of solid carbon on steel wool ultimately fouls the catalyst necessitating catalyst resupply. These factors result in high mass, volume and power demands for a Bosch system. Interplanetary transportation and surface exploration missions of the moon, Mars, and near-earth objects will require higher levels of loop closure than current technology cannot provide. A Bosch system can provide the level of loop closure necessary for these long-term missions if mass, volume, and power can be kept low. The keys to improving the Bosch system lie in reactor and catalyst development. In 2009, the National Aeronautics and Space Administration refurbished a circa 1980's developmental Bosch reactor and built a sub-scale Bosch Catalyst Test Stand for the purpose of reactor and catalyst development. This paper describes the baseline performance of two commercially available steel wool catalysts as compared to performance reported in the 1960's and 80's. Additionally, the results of sub-scale testing of alternative Bosch catalysts, including nickel- and cobalt-based catalysts, are discussed.
\end{abstract}

\section{Nomenclature}

$\begin{array}{ll}\mathrm{AR} & =\text { Atmosphere Revitalization } \\ \mathrm{B}-\mathrm{CaTS} & =\text { Bosch Catalyst Test Stand } \\ \mathrm{CDRe} & =\text { Carbon Dioxide Reduction } \\ \mathrm{CO}_{2} & =\text { Carbon Dioxide } \\ \mathrm{CRA} & =\text { Carbon Dioxide Reduction Assembly } \\ \mathrm{GDC} & =\text { General Dynamics Corporation } \\ \mathrm{H}-\mathrm{Bosch} & =\text { Horizontal Bosch } \\ \mathrm{ISS} & =\text { International Space Station } \\ \text { LEO } & =\text { Low Earth Orbit } \\ \text { MSFC } & =\text { Marshall Space Flight Center } \\ \text { NASA } & =\text { National Aeronautics and Space Administration } \\ \text { OGA } & =\text { Oxygen Generation Assembly } \\ \text { RWGS } & =\text { Reverse Water-Gas Shift } \\ \mu-G C & =\text { Micro-Gas Chromatograph }\end{array}$

${ }^{1}$ Aerospace Engineer, Environmental Control and Life Support Systems Development Branch, Bldg 4755 Room 403-7, Huntsville, AL 35812.

${ }^{2}$ Test Engineer, Environmental Control and Life Support Systems Development Branch, Bldg 4755 Room 115, Huntsville, AL 35812. 


\section{Introduction}

$\mathrm{T}$ he Atmosphere Revitalization (AR) system aboard the International Space Station (ISS) includes a number of technologies to manage air quality. Among these is the Carbon Dioxide Reduction Assembly (CRA) that employs a Sabatier reactor to reduce metabolic carbon dioxide $\left(\mathrm{CO}_{2}\right)$ with hydrogen to form water and methane. Product water is ultimately sent to the Oxygen Generation Assembly (OGA) for electrolysis resulting in the production of oxygen and hydrogen. Oxygen is returned to the cabin while hydrogen is recycled back to the CRA for further processing of $\mathrm{CO}_{2}$. Methane from the CRA is vented overboard resulting in a net loss of system hydrogen. The cost of water resupply and electrolysis to replace the lost hydrogen is acceptable for missions in low earth orbit (LEO), such as ISS. However, for long-term manned space missions outside of LEO, where resupply will be significantly more difficult and costly, AR systems must incorporate technology capable of greater recovery to "close the loop" on essential oxygen and hydrogen. For the CRA, it is possible to incorporate a methane reduction system to further reduce the methane and recover all or a portion of the hydrogen. As an alternative to "CRA plus methane reduction" architectures, a Bosch system has been proposed to maximize loop closure.

Bosch development at the National Aeronautics and Space Administration (NASA) began in the 1960's. Bosch was later chosen as the baseline carbon dioxide reduction (CDRe) technology for Space Station Freedom and was tested at the Marshall Space Flight Center (MSFC). ${ }^{1}$ In the early 1990's, a head-to-head performance comparison was completed at MSFC between Bosch and Sabatier technology. Sabatier technology was ultimately chosen for ISS due to lower development risk and lower mass, volume, and power requirements. Additionally, it was determined that complete oxygen and hydrogen recovery was not necessary for a space station application. However, it was noted in the final test report that the Bosch was a desirable technology for long-duration missions where resupply was not readily available. ${ }^{2}$ As NASA considers missions beyond LEO, Bosch technology is again of interest for CDRe. The Bosch process is expressed by the overall reaction as shown in equation 1.

$$
\mathrm{CO}_{2}+2 \mathrm{H}_{2} \rightarrow \mathrm{C}+2 \mathrm{H}_{2} \mathrm{O}
$$

Traditional Bosch operation (1960-70's) involved the reduction of $\mathrm{CO}_{2}$ with hydrogen to form water and solid carbon over a steel wool catalyst. These systems required a large recycle ratio (approximately 15:1) and reactor temperatures around $650^{\circ} \mathrm{C}$ for optimum performance in a single reactor. ${ }^{3}$ The resulting carbon formed on the catalyst and was collected in a replaceable cartridge. Water was collected for further processing in an OGA for oxygen production and hydrogen recovery. A Bosch system developed and tested in the 1990's used a nickel wool catalyst, thus reducing the operating temperature to $560^{\circ} \mathrm{C}$ while still requiring a large recycle ratio. Key concerns with all generations of Bosch technology have included high operating temperatures, low single-pass efficiency (large recycle ratio), catalyst fouling, and carbon containment. ${ }^{1-3}$ While carbon containment must be addressed by specific reactor design parameters, the others can be addressed with improved catalyst development and potentially by configuring the process as two reactors in series, rather than a single reactor.

Although the Bosch reaction can be expressed as equation 1 above, the system is actually more complex and involves three reactions: the reverse water-gas shift (RWGS), hydrogenation, and Boudouard reactions, as shown in equations $2-4$, respectively.

$$
\begin{gathered}
\mathrm{CO}_{2}+\mathrm{H}_{2} \rightarrow \mathrm{CO}+\mathrm{H}_{2} \mathrm{O} \\
\mathrm{CO}+\mathrm{H}_{2} \rightarrow \mathrm{C}+\mathrm{H}_{2} \mathrm{O} \\
2 \mathrm{CO} \rightarrow \mathrm{C}+\mathrm{CO}_{2}
\end{gathered}
$$

The reduction of $\mathrm{CO}_{2}$ with hydrogen may proceed via RWGS to produce carbon monoxide and water, or via the Sabatier reaction to produce methane and water. Significant research has been completed to explore the RWGS reaction over a number of catalysts including iron, nickel, cobalt, copper, zinc-oxide, and others. ${ }^{4-14}$ Development of RWGS catalysts has focused on selectivity as well as temperature optimization. Similarly, significant research has been completed to explore the Boudouard reaction. However, most research has been limited to nickel, cobalt, and iron catalysts. ${ }^{15-31}$ Research has shown that over a steel wool catalyst, the RWGS requires high temperatures for maximum conversion to carbon monoxide. However, conversion is only about $10 \%$ for a single pass. The Boudouard and hydrogenation reactions prefer lower temperatures for maximum conversion to carbon. Thus, the high temperature operation of developmental Bosch reactors has favored the RWGS over the carbon-formation reactions. This has been necessary to maximize the conversion within the reactor, but has resulted in large recycle 
requirements (and greater power, mass, and volume to accommodate). Thus, two approaches can be made to improving Bosch performance for continued development:

1) Use of improved catalysts in the Bosch reactor to minimize temperature requirements and recycle rates and to improve reaction selectivity.

2) Separation of the single Bosch reactor into a series reactor with the first reactor dedicated to RWGS and the second reactor dedicated to the hydrogenation and/or Boudouard reaction, allowing each reactor to be optimized for temperature, size, etc., independently.

It is the intent of this team to pursue both approaches for ongoing Bosch development.

Preliminary testing has begun at MSFC for Bosch development using two test stands including the HorizontalBosch (H-Bosch), originally developed and built in the 1980's by Life Systems, Inc., and the Bosch Catalyst Test Stand (B-CaTS), built at MSFC for catalyst testing. Bosch baseline testing was completed in the H-Bosch incorporating a traditional wound steel wool catalyst and a shredded steel wool catalyst. Alternative catalyst testing has been completed in the B-CaTS over shredded steel wool, a nickel foam, a nickel wool, an aluminum-supported nickel and an aluminum-supported cobalt. This paper provides detailed methods and results of this testing. Additionally, conclusions and future work are addressed.

\section{Hardware Description}

Two pieces of hardware were used for the testing described in this paper including the Horizontal Bosch (HBosch) Carbon Dioxide Reduction Assembly, and the Bosch Catalyst Test Stand (B-CaTS). The systems are briefly described below.

\section{A. Horizontal Bosch (H-Bosch) Test Stand}

The Horizontal Bosch (H-Bosch) Test Stand, shown in Figure 1, consists of a number of component subsystems located at the MSFC Environmental Control and Life Support Systems (ECLSS) development facility. The H-Bosch reactor system was originally developed by Life Systems, Inc. and is described in detail in another location. ${ }^{1}$ Briefly, the system is made up of two reactor assemblies, a condensing heat exchanger, a system compressor and various flow controllers, tubing, pressure transducers, thermocouples and other instrumentation necessary for operation. The reactor assemblies are custom-designed and constructed to withstand the harsh environment required to carry out the Bosch reaction. Each reactor assembly consists of a coiled tube-in-tube heat exchanger wrapped around a cylindrical reactor body. A heater sheath runs axially through the center of the reactor body to approximately three quarters of the length of the reactor. The heater sheath allows a cartridge heater to be inserted for reactor heating without exposing the heater to the internal reactor gas mixture.

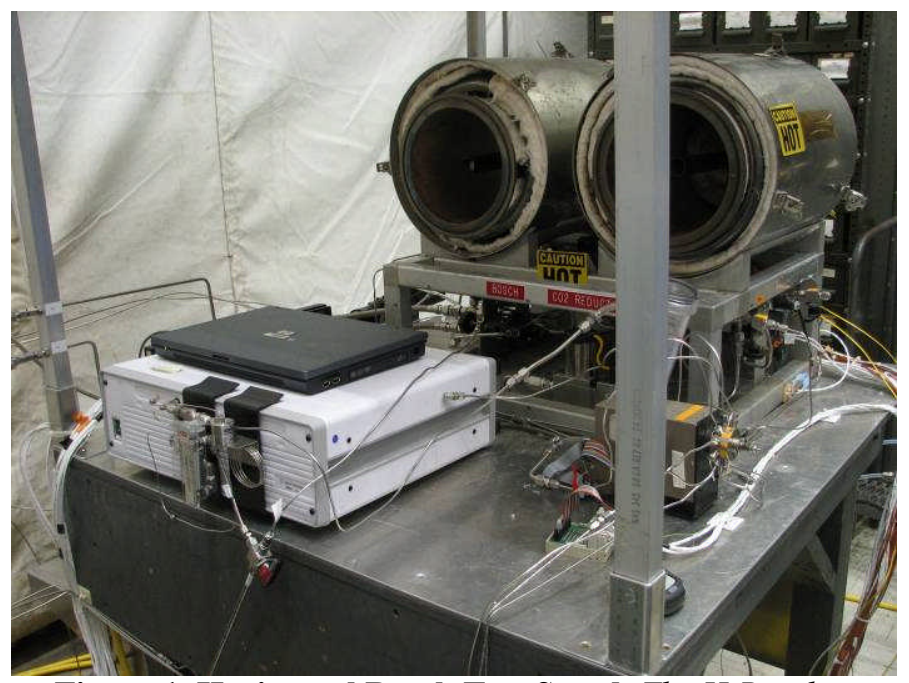

Figure 1. Horizontal Bosch Test Stand. The H-Bosch is located at the Environmental Control and Life Support Systems Development Facility at MSFC. 
The sheath is encircled by a thin open-ended tube resulting in a one-quarter inch annular channel between the two. After passing through the regenerative heat exchanger, feed gas flows through the channel, where additional heat is added, and out the open end into the reactor. Upon entering the reactor, gas flows radially outward through the reactor catalyst as well as axially in the direction opposite of entry. The gas exits the reactor through a ring-shaped distributor around the base of the feed tube. The hot gas must then pass counter-currently to the feed gas through the heat exchanger. A removable faceplate is located at the end of the reactor body opposite the heater. The reactor effluent stream is cooled in a condensing heat exchanger and recycled through a compressor. The product water collects in an accumulator resting on a scale, allowing water production to be monitored in near-real time. Catalyst material is packed into cylindrical cartridges designed to slip over the heater sheath and an internal thermocouple well. The catalyst cartridge sides are made of a metal mesh in order to permit gas flow. All internal surfaces of a cartridge are lined with ceramic batting before being packed with catalyst in an attempt to contain the carbon produced by the reaction. Once a cartridge is packed, it is inserted into the reactor, and the faceplate is closed and sealed.

Control is accomplished with a custom interface developed with National Instruments' LabVIEW programming environment (Austin, TX). This control system allows for manipulation of valves and facilitates constant data collection from thermocouples, pressure transducers, and other instrumentation. Feed gases are provided from gas cylinders. Chilled water is supplied to the condensing heat exchanger by a system chiller. An Agilent micro-Gas Chromatograph ( $\mu$-GC) (Santa Clara, CA) is used to monitor gas composition. The $\mu$-GC is programmed for continuous analysis resulting in approximately three and one-half minutes between samples. The sample location is selected from several available sites within the system using a multiport valve manufactured by Valco Instruments Company (Houston, TX). The results of each analysis are immediately delivered to the primary control system providing the capability to control recycle stream composition in near real-time by manipulating carbon dioxide and hydrogen feed rates.

\section{B. Bosch Catalyst Test Stand (B-CaTS)}

The B-CaTS, shown in Figure 2, is a scaleddown, single-pass version of the $\mathrm{H}$-Bosch that facilitates more efficient testing of Bosch catalyst properties. System feed gases pass through individual mass flow controllers and are mixed with other gases to form the reactor feed stream. Reactant gases flow through a quartz reactor tube described in detail below. The quartz reactor tube is packed with a specific mass of the catalyst under investigation. The product gas from the reactor tube is vented outside the building.

System pressure is controlled with a back pressure regulator at the reactor outlet. A vacuum pump allows the system to be operated at pressures as low as 4 psia. The maximum operating pressure is limited to 20 psia. Pressure transducers and thermocouples provide feedback for monitoring the pressure and temperature at the inlet and outlet of the reactor. A micro-Gas Chromatograph ( $\mu-G C)$ (Agilent Technologies, Santa Clara, CA) is used for process gas sampling. A multi-port valve (Valco Instruments, Houston, TX) allows selection of the point within the system from which the GC sample stream is drawn. In the current configuration, only the reactor inlet and reactor outlet are sampled.

The B-CaTS reactor consists of a quartz tube with an internal diameter of $46 \mathrm{~mm}$ and length of $610 \mathrm{~mm}$ (National Scientific Company, Quakertown, PA). The reactor tube is inserted into a Thermolyne Basic Tube Furnace (Thermo Scientific, Waltham, MA).

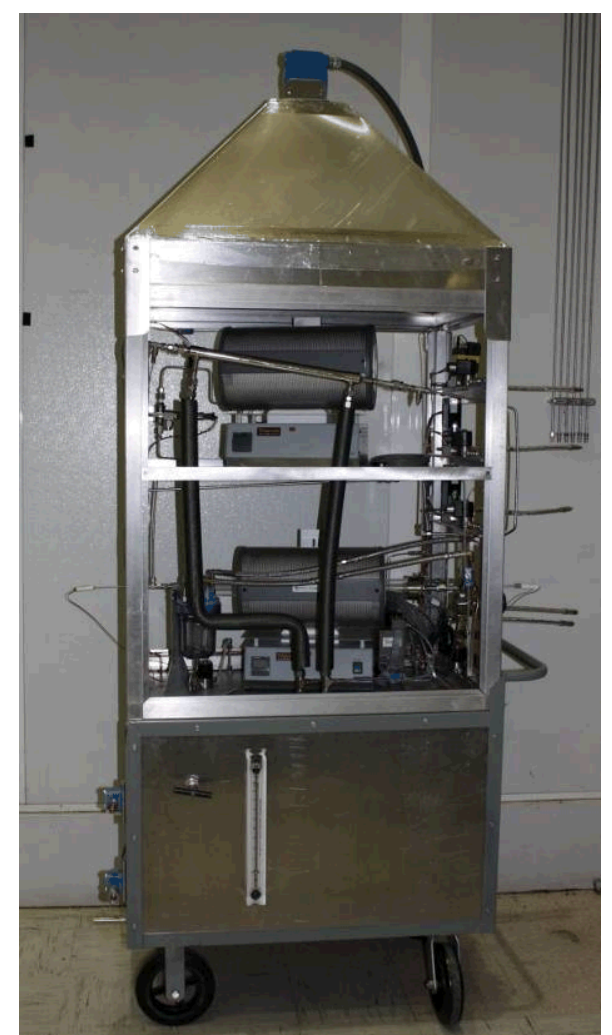

Figure 2. Bosch Catalyst Test Stand. The B-CaTS provides a quartz reactor in a tube furnace for Bosch catalyst testing. 
When in place, the ends of the quartz tube extend beyond the sides of the furnace. Each tube end is sealed with a Vacuum Sealing Assembly (MTI Corporation, Richmond, CA), providing a connection for system tubing. The furnace is controlled by a built-in temperature control system and is capable of maintaining temperatures of 100$1200 \pm 5^{\circ} \mathrm{C}$. Pressure, temperature, gas composition, and other variables are manipulated through a custom software control interface developed within the LabVIEW programming environment (National Instruments, Austin, TX). Data acquisition is carried out via a proprietary application called PACRATS.

\section{Methods}

Two separate tests conducted at the MSFC ECLSS Test Facility will be reported. The Bosch Baseline Test was first conducted using the H-Bosch Test Stand, followed by the Alternative Catalyst Test conducted using the BCaTS. Each test is described in detail below.

\section{A. Bosch Baseline Testing}

Two varieties of steel wool catalyst were purchased from Global Material Technologies (Buffalo Grove, IL) for Bosch Baseline Testing. Strands of the first, referred to as "wound" wool and shown in Figure 3, had an average diameter of $25 \mu \mathrm{m}$ and a length of $61 \mathrm{~cm}$. Strands were supplied in $10.2 \mathrm{~cm}$-wide bundles. Strands of the second, referred to as "shredded" wool and shown in Figure 4, had an average diameter of $25 \mu \mathrm{m}$ and an average length of $0.3-0.7 \mathrm{~cm}$ and were supplied as a loose product.

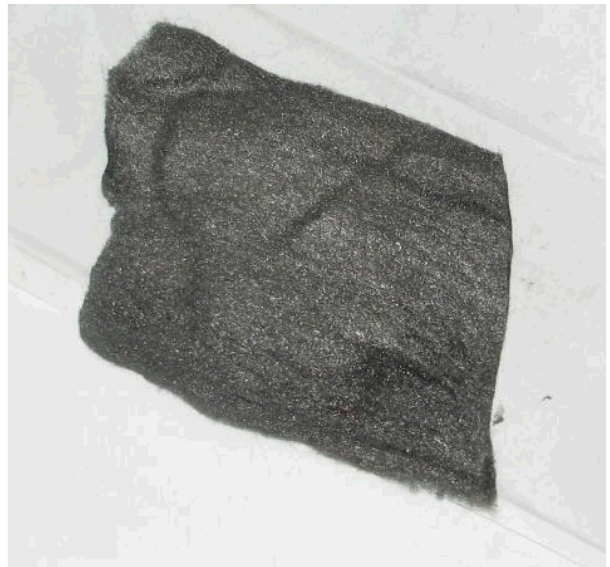

Figure 3. Wound Steel Wool. Wound steel wool sample is shown cut from a longer strip.

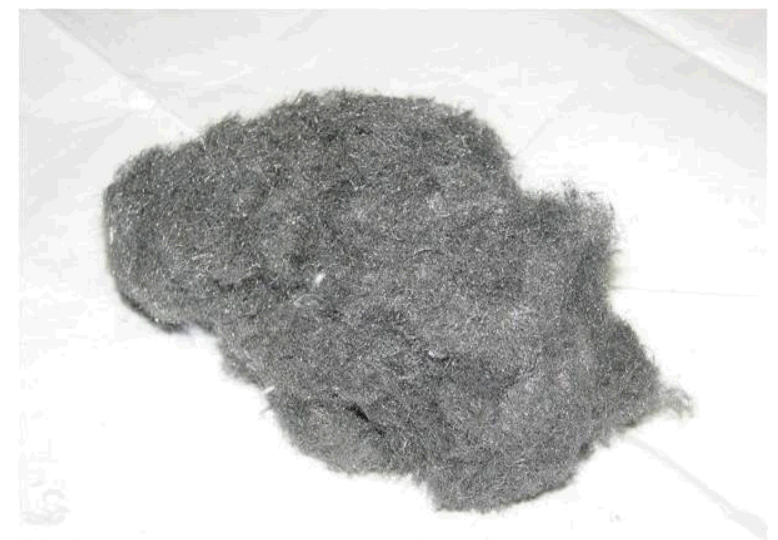

Figure 4. Shredded Steel Wool. Shredded steel wool was used in both Bosch Baseline and Alternative Catalyst Testing.

Three trials were conducted with each catalyst for a total of six trials. Catalyst trials incorporated $50 \mathrm{~g}, 150 \mathrm{~g}$, and $300 \mathrm{~g}$ of each catalyst operated for approximately 45,72 and 4 hours, respectively. The run order of each catalyst and catalyst quantity, shown in Table 1, was randomized.

Table 1. Bosch Baseline Test Trial Description. Catalyst trials were randomized and run in the order shown below and included three quantities of two types of catalyst.

\begin{tabular}{|c|c|c|}
\hline Trial & Steel Wool & Quantity (g) \\
\hline 1 & Shredded & 150 \\
\hline 2 & Wound & 150 \\
\hline 3 & Shredded & 300 \\
\hline 4 & Shredded & 50 \\
\hline 5 & Wound & 300 \\
\hline 6 & Wound & 50 \\
\hline
\end{tabular}




\section{Catalyst Pre-Treatment}

Before use, all steel wool catalyst was pretreated as described by Holmes et. al. ${ }^{3}$ Briefly, the catalyst was repeatedly cleaned in a 3\% hydrochloric acid solution, rinsed in de-ionized water, and baked for 45 minutes at $207^{\circ} \mathrm{C}$. Catalyst was loaded into the $\mathrm{H}$-Bosch cartridge immediately after removal from the oven.

\section{Catalyst Loading}

Within the H-Bosch reactors, the catalyst was held in exchangeable cartridges such as the one pictured in Figure 5. Prior to loading, catalyst cartridges were lined with $1.27 \mathrm{~cm}$-thick Fiberfrax (Niagara Falls, NY) Durablanket ${ }^{\mathbb{B}} \mathrm{S}$ insulation in order to contain the product carbon inside the cartridge. For wound steel wool, the catalyst strands were spread apart by hand to increase the volume and exposed surface area. The strands were wound around the core of the cartridge. For shredded steel wool, the catalyst was distributed evenly throughout the available cartridge space. After the catalyst was loaded, two layers of insulation were placed on top of the catalyst and the cartridge lid was fixed in place with steel wire. Lastly, cartridges were installed into the H-Bosch reactor for operation.

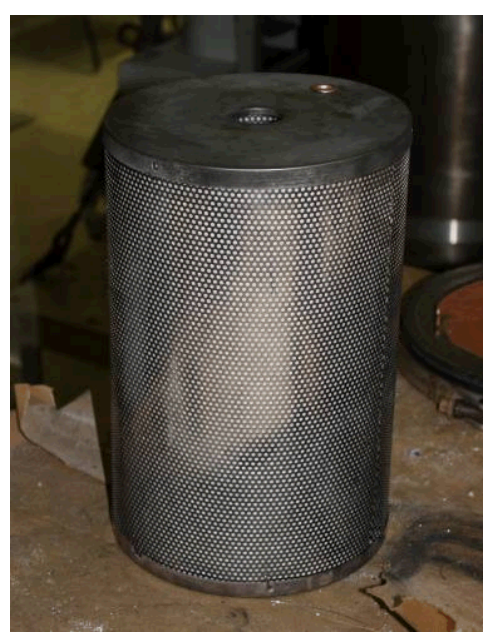

Figure 5. H-Bosch Cartridge. The H-Bosch cartridge was lined with insulation and packed with shredded or wound steel wool catalyst.

\section{H-Bosch Operation}

Following installation of the cartridge, the reactor faceplate was attached and sealed with a gasket and v-clamp. The system was then leak checked with $\mathrm{CO}_{2}$. A continuous purge flow of $\mathrm{CO}_{2}$ was fed to the system while the reactor was heated. $\mathrm{H}_{2}$ was introduced to the system once the reactor reached at least $290^{\circ} \mathrm{C}$. Operation was assumed to be at steady-state when the reactor reached $565^{\circ} \mathrm{C}$, though the target temperature was $650^{\circ} \mathrm{C}$. The water collection rate was verified every two hours by opening a drain valve and catching the product water in a graduated cylinder. The collected volumes were recorded at each data point. Throughout the tests, $\mathrm{CO}_{2}$ and $\mathrm{H}_{2}$ feed rates were varied slightly to maintain the maximum apparent reaction rate as determined subjectively by system pressure and temperature variations, component concentrations, and water production rate. A $\mu$-GC was used to monitor the recycle stream during testing.

\section{Cartridge Removal}

At the end of each trial, the system was purged with nitrogen and allowed to cool below $100^{\circ} \mathrm{C}$. The cartridge was removed from the reactor, opened, and photographed. Carbon and insulation material was stored for future analysis.

\section{B. Alternative Catalyst Testing}

Five materials were tested for catalytic activity toward the RWGS reaction, the Boudouard reaction, and the Hydrogenation reaction. Catalyst preparation, reactor loading, and testing are discussed below. 


\section{Catalyst Preparation}

The catalysts investigated in the Alternative Catalyst Test were the shredded steel wool used in the Baseline test, nickel foam, aluminum foamsupported nickel, aluminum foam-supported cobalt, and a nickel wool catalyst developed for the 1990's Bosch reactor.

Shredded steel wool was prepared as described above. Occasionally, the steel wool was stored after preparation in a pure nitrogen environment at $4-8$ psig. All prepared steel wool was used within 24 hours of preparation.

$\mathrm{INCOFOAM}^{\circledR}$ nickel foam sheets with a pore size of $590 \mu \mathrm{m}$ were purchased from Novamet Specialty Products Corporation (Wyckoff, NJ). For each trial series, twenty-two foam disks of approximately 4.5 $\mathrm{cm}$ diameter were cut from the foam as shown in Figure 6. Total catalyst weight averaged approximately $16.5 \mathrm{~g}$. No additional pre-treatment was performed on the nickel foam.

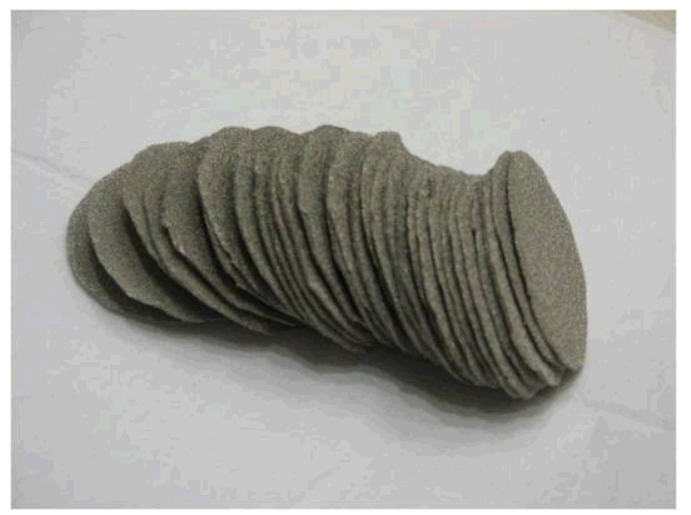

Figure 6. Nickel Foam Catalyst. Nickel foam was cut into $4.5 \mathrm{~cm}$ disks for testing.

Duocel $^{\circledR}$ aluminum foam $(9-11 \%$ density, 10 pores per inch), pictured in Figure 7, was purchased from ERG Materials and Aerospace Corporation (Oakland, CA) as a catalyst support. The foam was cut into cylinders with diameter and height of approximately $4.5 \mathrm{~cm}$ and $2.54 \mathrm{~cm}$, respectively. These support cylinders were used to prepare aluminum-supported nickel and aluminum-supported cobalt catalysts as described below.

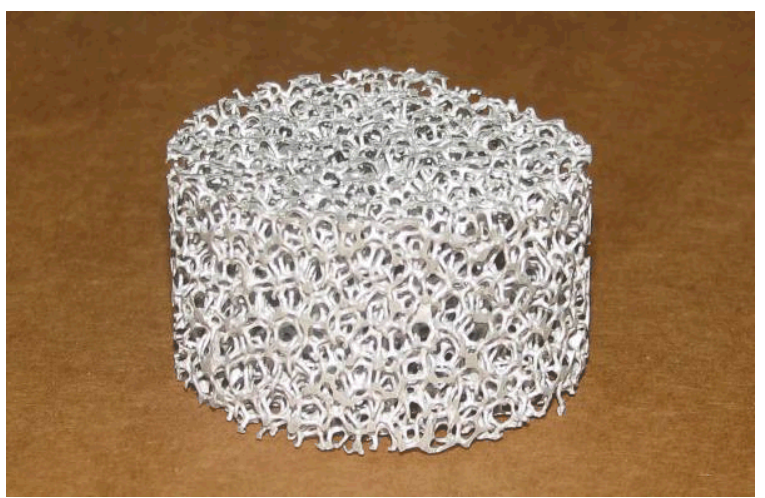

Figure 7. Aluminum Foam Support. Aluminum foam was used as a support for the aluminumsupported nickel and aluminum-supported cobalt catalysts.

Nickel or cobalt was plated on an aluminum support using an Electroless Nickel or Electroless Cobalt Plating Kit from Caswell Plating (Lyons, NY). Briefly, aluminum supports were zincated for one minute then submerged in nickel or cobalt plating solutions for 45 minutes. Catalysts were removed from solution, rinsed, and stored under nitrogen at $4-8$ psig until used. All aluminumsupported catalysts were used within 24 hours of preparation. Aluminum-supported nickel and cobalt catalysts are shown in Figure 8 and Figure 9, respectively.

Nickel wool catalyst, shown in Figure 10, was obtained from a Vertical-Bosch reactor cartridge

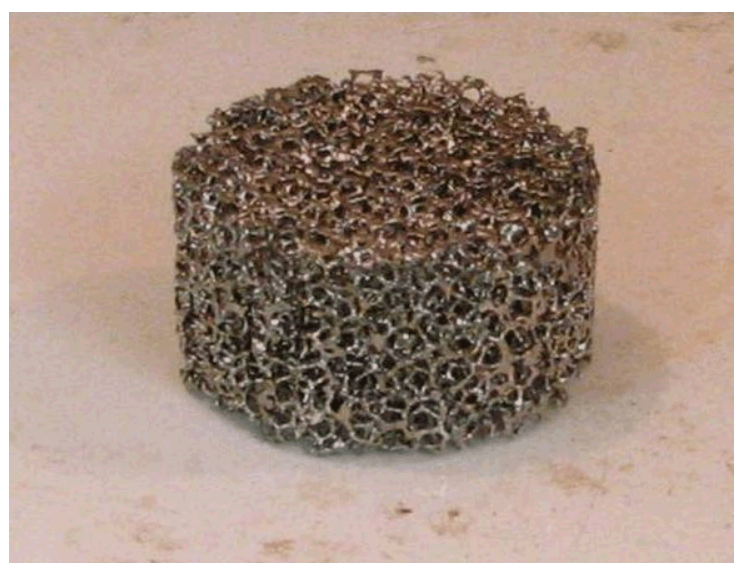

Figure 8. Aluminum-supported Nickel. Nickel was plated on an aluminum-foam support to make the Nickel-Aluminum catalyst. 


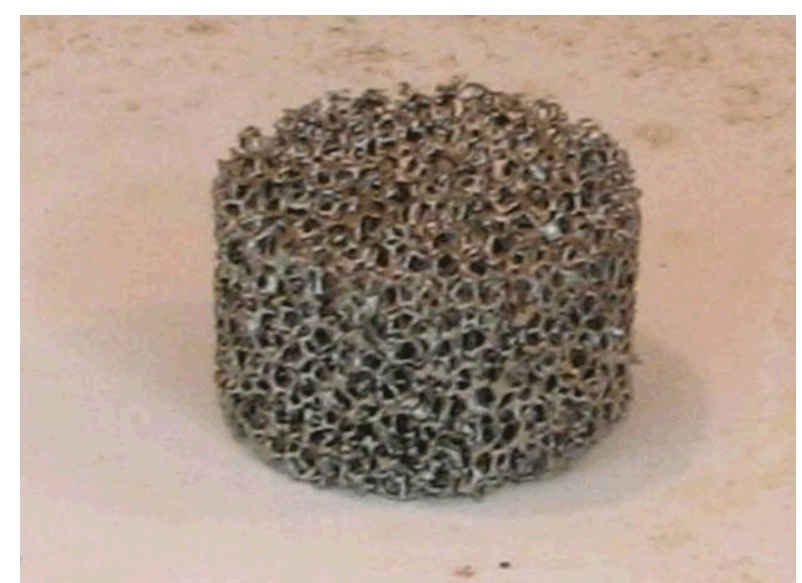

Figure 9. Aluminum-supported Cobalt. Cobalt was plated on an aluminum-foam support to make the Cobalt-Aluminum catalyst.

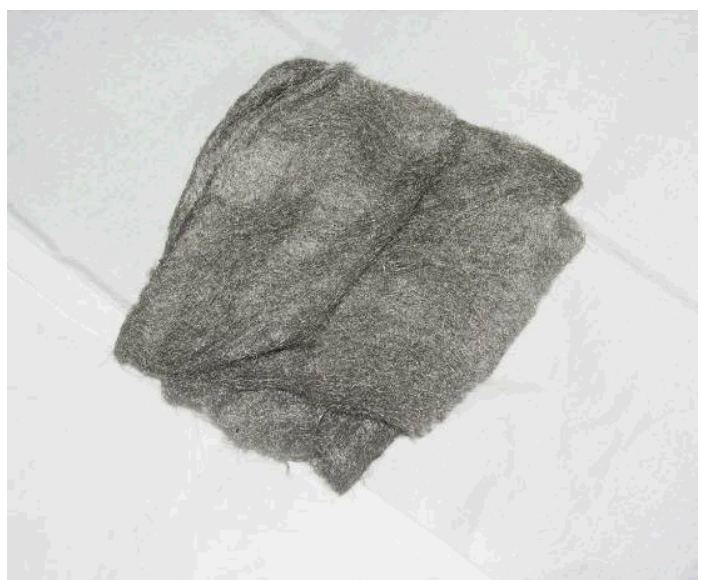

Figure 10. Nickel Wool. Nickel wool catalyst is a proprietary catalyst obtained from a Vertical Bosch developed in the late 1980's.

located at MSFC. Preparation of the catalyst is a proprietary method and will not be discussed here. No additional treatment was necessary before use of the catalyst.

\section{Reactor Loading}

Before loading catalyst, each quartz reactor tube was cleaned with 70\% isopropyl alcohol and allowed to dry. Each catalyst was loaded into the center of the reactor with three Durablanket ${ }^{\circledR} \mathrm{S}$ insulation disks on either side to contain carbon, as shown in Figure 11. Finally, the loaded quartz tube was inserted into the tube furnace.

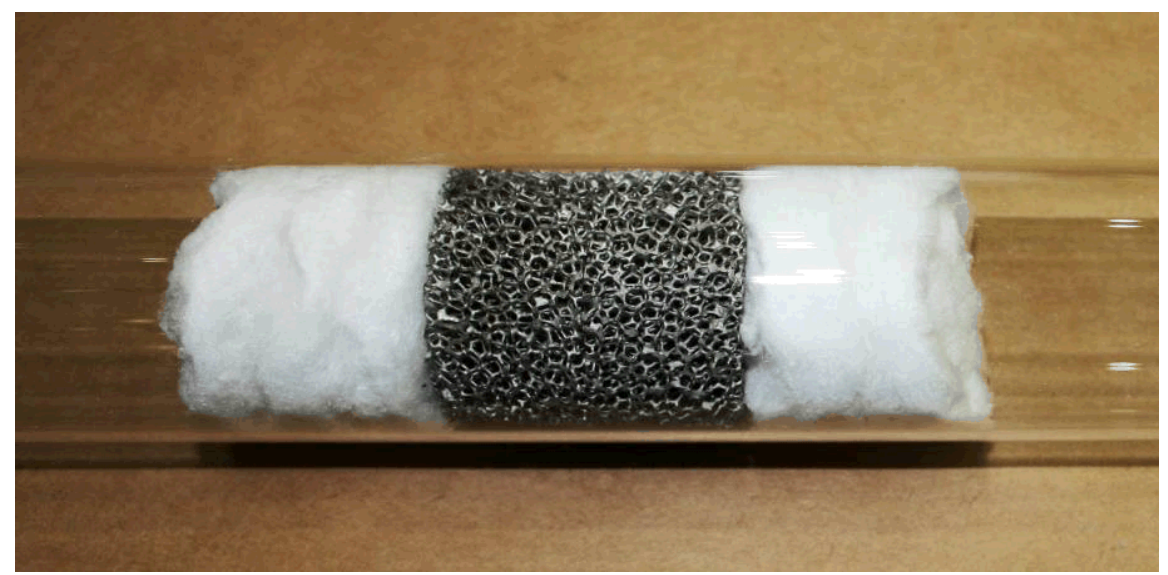

Figure 11. Packed B-CaTS Reactor Tube. Each catalyst was packed into a quartz reactor tube with three insulation disks on either side. Aluminum-

supported cobalt is shown above.

\section{Testing}

Prior to testing, each catalyst was de-oxidized by flowing a $50 \mathrm{~mol} \% \mathrm{H}_{2} / 50 \mathrm{~mol} \% \mathrm{~N}_{2}$ stream across the catalyst while heating to the first testing temperature $\left(250^{\circ} \mathrm{C}\right.$ for steel wool and $200^{\circ} \mathrm{C}$ for all other catalysts) and maintaining for 30 minutes. The system was purged with nitrogen before beginning testing. Each catalyst sample was tested over four temperatures for activity for one of three reactions: RWGS, Hydrogenation, or Boudouard. Steel wool was tested at $250^{\circ} \mathrm{C}, 400^{\circ} \mathrm{C}, 500^{\circ} \mathrm{C}$, and $650^{\circ} \mathrm{C}$. Nickel foam and aluminum-supported nickel and cobalt were tested at $200^{\circ} \mathrm{C}, 300^{\circ} \mathrm{C}, 400^{\circ} \mathrm{C}$, and $500^{\circ} \mathrm{C}$. Nickel wool was tested at $200^{\circ} \mathrm{C}, 350^{\circ} \mathrm{C}, 450^{\circ} \mathrm{C}$, and $600^{\circ} \mathrm{C}$. 


\section{Catalyst Analysis}

Samples of each catalyst used in Baseline or Alternative Catalyst Testing were sent to Beckman Coulter's Particle Characterization Applications Laboratory in Miami, FL for BET analysis to determine specific surface area. Table 2 provides the values of surface area determined by the laboratory and the gas used for the analysis.

Table 2. BET Surface Area Analysis of Catalysts. The surface area of each catalyst is reported from a BET analysis. The gas used for each BET analysis is noted. "ND" indicates that no data was available.

\begin{tabular}{|l|c|c|}
\hline \multicolumn{1}{|c|}{ Catalyst } & $\begin{array}{c}\text { Measured Surface Area } \\
\left(\mathbf{m}^{\mathbf{2}} / \mathbf{g}\right) \text { from BET Analysis }\end{array}$ & $\begin{array}{c}\text { Gas Used for BET } \\
\text { Analysis }\end{array}$ \\
\hline Wound Steel Wool & 0.056 & Nitrogen \\
\hline Shredded Steel Wool & 1.761 & Nitrogen \\
\hline Nickel Foam & ND & Krypton \\
\hline Nickel on Aluminum Support & 0.263 & Nitrogen \\
\hline Cobalt on Aluminum Support & 0.300 & Nitrogen \\
\hline Nickel Wool & 0.022 & Nitrogen \\
\hline
\end{tabular}

\section{Results and Discussion}

Bosch Baseline Testing and Alternative Catalyst Testing were completed at MSFC in an attempt to advance Bosch and Bosch-related technology. The results of this testing are reported and discussed below.

\section{A. Bosch Baseline Testing}

Bosch Baseline testing was completed with two steel wool catalysts. The first catalyst, a wound steel wool, most closely mimicked that used in testing completed in the 1970's by General Dynamics Corporation (GDC). ${ }^{3}$ The second catalyst, a shredded steel wool, is identical in composition to that of the first catalyst. However, the shredded steel wool had a significantly larger specific surface area (more than 30 times greater according to BET analysis performed by Beckman Coulter) that may be attributed to the "shredded" structure of the catalyst. Three trials were completed for each catalyst. Trials with $50 \mathrm{~g}$ of catalyst were conducted to determine the maximum quantity of carbon that could be formed on each catalyst. Trials with $150 \mathrm{~g}$ of catalyst were conducted to compare performance in the H-Bosch with a very similar system tested in the 1970s. Trials with $300 \mathrm{~g}$ of catalyst were conducted to determine the carbon capacity of the cartridge. Reaction rate data were collected from all trials. However, no conclusions could be drawn due to unexpected differences in total recycle flow rates between trials.

\section{Specific Carbon Formation}

Trials with $50 \mathrm{~g}$ of catalyst were conducted to evaluate the maximum quantity of carbon that could be formed per gram of catalyst on each steel wool catalyst. It was originally intended that the reactor would be operated until the catalyst was entirely deactivated as determined by the cessation of water production. Shredded steel wool and wound steel wool were reacted at temperature for a total of 40.5 and 30.5 hours, respectively. During this time, neither catalyst displayed a decreased water production rate or any other indication of deactivation. Both tests were ultimately terminated due to a pressure drop across the reactor assembly of greater than $12 \mathrm{psid}$. This value for the limiting pressure drop was determined prior to testing as a safety stop point intended to prevent excessive accumulation of carbon, which could lead to reactor damage or contamination of the rest of the system. As seen previously in Table 1, trials utilizing $50 \mathrm{~g}$ of catalyst were conducted fourth and sixth in the testing order. It is hypothesized that during each trial, carbon build-up in the regenerative heat exchanger increased as a result of carbon escaping from the catalyst cartridge or depositing inside the heat exchanger. This accumulation of carbon from previous trials partially obstructed the heat exchanger, resulting in a premature pressure drop increase in the reactor. Because the catalysts were not run to deactivation in these, or any other trials, a value for maximum specific carbon formation could not be determined for either catalyst in this testing. Despite these limitations, carbon formation values of $23 \mathrm{~g}$ carbon $/ \mathrm{g}$ shredded steel wool and $21 \mathrm{~g}$ carbon $/ \mathrm{g}$ wound steel wool were achieved at the conclusion of these two trials. These values correspond with that reported by GDC of $23 \mathrm{~g}$ carbon/g steel wool catalyst. Since no indication of catalyst deactivation was observed in these trials, it is probable that the maximum specific carbon formations of the two steel wool catalysts tested are significantly higher than the values currently observed. 


\section{Cartridge Carbon Capacity}

Trials of $300 \mathrm{~g}$ of catalyst were conducted specifically to determine the carbon capacity of the cartridge. However, due to a very high pressure drop early in the test, shredded and wound steel wool were only run for 3.8 and 4.3 hours, respectively. Upon opening the cartridges to observe the carbon, it was clear that the cartridge was not packed to capacity. The carbon produced in both trials was very loose and dusty compared to other trials, which produced dense, solid "bricks" of deposited carbon in the cartridge. Additionally, un-consumed catalyst could clearly be seen in some sections of the carbon. The largest quantities of carbon in the cartridges were observed during the $150 \mathrm{~g}$ catalyst trials, in which testing was conducted for 72 hours without exceeding the maximum allowable reactor assembly pressure drop. The maximum carbon observed during testing was $3166 \mathrm{~g}$ on $150 \mathrm{~g}$ of wound steel wool. The resulting carbon had to be chiseled out of the cartridge. A similar brick was observed when testing $150 \mathrm{~g}$ of shredded steel wool as seen in Figure 12.

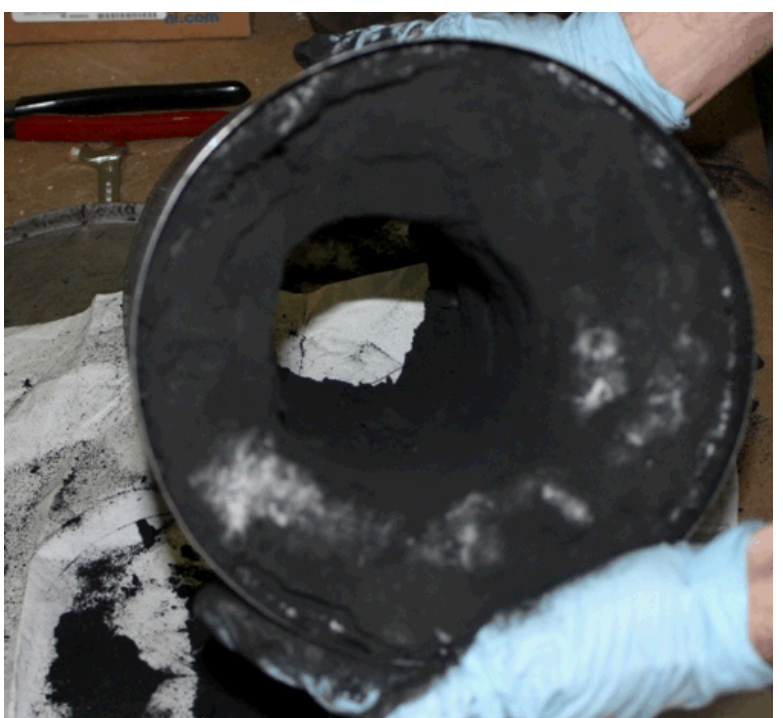

Figure 12. Carbon Brick from H-Bosch. Carbon formed on shredded steel wool within a H-Bosch cartridge. The center and ends of the cartridge have been removed to show the structure of the brick. The white area is insulation embedded with carbon.

\section{Performance Comparison}

Trials with $150 \mathrm{~g}$ catalyst were conducted to provide a direct comparison to testing completed in the 1970's by GDC. GDC operated a Bosch reactor of similar size to the H-Bosch with $150 \mathrm{~g}$ wound steel wool for 72 hours. Table 3 provides operation data from both GDC testing and testing completed at MSFC.

Table 3. Comparison of Bosch Operation. Bosch operation data collected at MSFC is shown for two steel wool catalysts along with data reported by GDC in the 1970's. Error shown in standard deviation.

\begin{tabular}{|c|c|c|c|c|}
\hline \multirow{2}{*}{ Metric } & \multicolumn{3}{|c|}{ Type of Catalyst - Data Source } & \multirow{2}{*}{ Units } \\
\hline & Shredded-MSFC & Wound - MSFC & Wound - GDC & \\
\hline Overall Water Production Rate & 1.51 & 1.93 & 2.39 & $\mathrm{~g} / \mathrm{min}$ \\
\hline Average Reactor Temperature & $657 \pm 4$ & $657 \pm 3$ & 679 & ${ }^{\circ} \mathrm{C}$ \\
\hline Average Sys tem Pressure Pre-Reactor & $27.9 \pm 1.6$ & $28.5 \pm 1.0$ & 20 & psi \\
\hline Average $\mathrm{CO}_{2}$ Feed Rate & $1.00 \pm 0.28$ & $1.36 \pm 0.15$ & 1.49 & SLPM \\
\hline Average $\mathrm{H}_{2}$ Feed Rate & $2.19 \pm 0.56$ & $2.96 \pm 0.35$ & 2.99 & SLPM \\
\hline Average Recycle Flow Rate & $63 \pm 4$ & $66 \pm 3$ & 70 & SLPM \\
\hline Overall Recycle Ratio & 18.7 & 14.3 & 14.6 & \\
\hline \multicolumn{5}{|l|}{ Average Recycle Composition } \\
\hline $\mathrm{H}_{2}$ & $23.5 \pm 12.1$ & $37.1 \pm 6.1$ & 33 & $\mathrm{~mol} \%$ \\
\hline $\mathrm{CO}_{2}$ & $36.9 \pm 29.4$ & $14.2 \pm 6.5$ & 14 & $\mathrm{~mol} \%$ \\
\hline $\mathrm{CO}$ & $31.0 \pm 18.3$ & $29.9 \pm 7.2$ & 33 & $\mathrm{~mol} \%$ \\
\hline $\mathrm{CH} 4$ & $8.6 \pm 7.6$ & $18.8 \pm 5.8$ & 20 & $\mathrm{~mol} \%$ \\
\hline
\end{tabular}

The performance of the Bosch in MSFC testing with both steel wool catalysts was slightly lower than that observed in GDC testing. Hydrogen and $\mathrm{CO}_{2}$ feed rates were slightly lower in MSFC testing corresponding to lower observed water production rates. This may be a result of several causes. First, the reactor operating temperature during GDC testing was slightly higher than that during operation at MSFC. Higher temperature operation would result in a faster RWGS reaction thus producing water more quickly and providing more carbon monoxide for carbon formation and further water production. Secondly, in testing by GDC, feed rates were controlled by a feedback system that 
constantly monitored the $\mathrm{CO}_{2}$ in the recycle stream. In testing at MSFC, recycle composition data was available only every 3.5-4 minutes due to the $\mu$-GC sample times. This subtle difference in recycle composition control could account for the observed variation in operation and production data. Thirdly, the MSFC and GDC reactor assemblies were not identical, and thus, differences in geometry may have played a role in the lower rates of reaction. Finally, the recycle flow rate was somewhat lower for the MSFC testing, which likely accounts for some of the decrease.

\section{B. Alternative Catalyst Testing}

Alternative Catalyst Testing was completed on five catalysts. Each catalyst was tested for activity towards the RWGS reaction, the Boudouard reaction, and the hydrogenation reaction at various temperatures. Table 4 provides a summary of the relative activity level of each catalyst for each reaction at the temperatures indicated. Relative activity is indicated by a ranking of "None," "Low," "Medium," and "High." The activity ranking of each catalyst is relative only to the other catalysts in this study. A "Medium/Low" relative activity is noted for the Boudouard reaction over nickel foam. These relative activities refer to the Boudouard reaction when in the presence of a carbon monoxide/hydrogen mixture and carbon monoxide alone, respectively. These will be discussed more in the Boudouard section below. Additionally, specific reaction rate, rate constants, and rate equation data for all catalysts are described below.

Table 4. Summary of Relative Activity of Catalysts for Bosch Reactions. Relative catalyst activity levels are indicated by Low, Medium, High or None. Results are valid only in the temperature ranges indicated.

\begin{tabular}{|l|c|c|c|c|}
\hline \multicolumn{1}{|c|}{ Catalyst } & $\begin{array}{c}\text { Temperature } \\
\text { Range (K) }\end{array}$ & Boudouard & RWGS & Hydrogenation \\
\hline Shredded Steel Wool & $523-923$ & High & High & High \\
\hline Nickel Foam & $473-773$ & Medium/Low & High & Medium \\
\hline Nickel on Aluminum & $473-773$ & None & None & None \\
\hline Cobalt on Aluminum & $473-773$ & None & Medium & None \\
\hline Nickel Wool & $473-873$ & Low & Medium & Low \\
\hline
\end{tabular}

\section{Reverse Water-Gas Shift Reaction}

The RWGS reaction, as shown in equation 2, has been studied over numerous catalysts including supported coppers, iron silicates, and iron oxides, among others. ${ }^{4-14}$ The commonly accepted mechanism for the catalyzed RWGS reaction begins with the dissociative adsorption of $\mathrm{CO}_{2}$ on the catalyst surface to form surface-bound $\mathrm{CO}$ and $\mathrm{O}$. Likewise, $\mathrm{H}_{2}$ dissociatively adsorbs onto the catalyst surface. $\mathrm{CO}$ desorbs from the surface while surfacebound hydrogen atoms react with surface-bound oxygen to form water, which is then desorbed. Taking the dissociative adsorption of $\mathrm{CO}_{2}$ to be the rate-determining step results in the rate expression shown in equation 5 .

$$
r=k\left(P_{\mathrm{CO}_{2}}\right)^{\alpha}\left(P_{\mathrm{H}_{2}}\right)^{\beta}
$$

Values of $\alpha$ and $\beta$ can vary with both catalyst and the ratio of $\mathrm{CO}_{2}$ and $\mathrm{H}_{2}$ partial pressures, as reported by Ginés et $a l .^{5}$ This variation was explained by the effect of hydrogen on the surface of metal catalysts. It was suggested that in $\mathrm{H}_{2}$-rich environments, metal surfaces undergo structural or phase transitions that affect $\mathrm{CO}_{2}$ dissociation, thus resulting in changes to the apparent reaction order.

In this study, the RWGS reaction was observed on all of the catalysts with the exception of aluminum-supported nickel. The results from each of the other catalysts are discussed below.

\section{a. RWGS over Shredded Steel Wool}

Shredded steel wool was shown to be active toward catalyzing the RWGS reaction at temperatures of $400^{\circ} \mathrm{C}$ and above in both hydrogen-rich and $\mathrm{CO}_{2}$-rich environments, as shown in Figure 13 and Figure 14, respectively. 


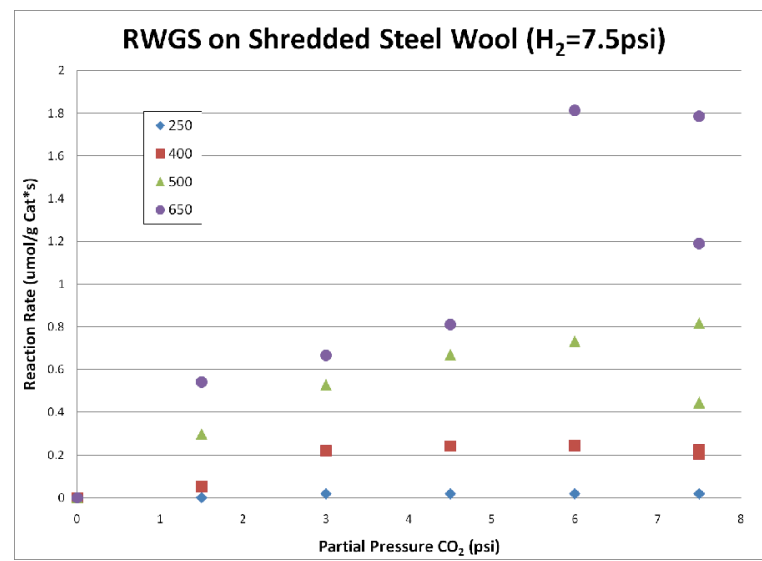

Figure 13. RWGS on Shredded Steel Wool (constant $\mathbf{H}_{2}$ ). $R W G S$ reaction rate versus the partial pressure of $\mathrm{CO}_{2}$ is shown with $\mathrm{H}_{2}$ partial pressure held constant at $7.5 \mathrm{psi}$.

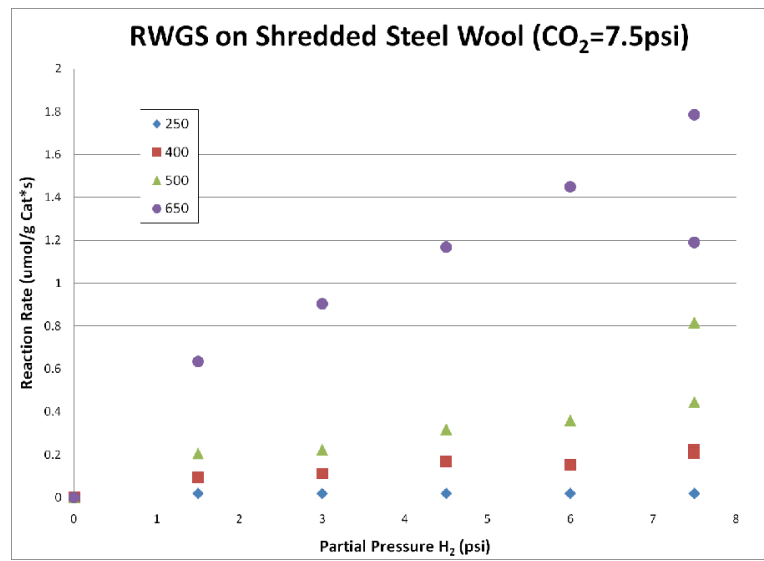

Figure 14. RWGS on Shredded Steel Wool (constant $\mathbf{C O}_{2}$ ). RWGS reaction rate versus the partial pressure of $\mathrm{H}_{2}$ is shown with $\mathrm{CO}_{2}$ partial pressure held constant at 7.5psi.

Using data from each of the reactive temperatures of shredded steel wool, values for $\alpha$ and $\beta$ were determined to be 0.55 and 0.54 , respectively. Figure 15, a plot of predicted versus experimental rate values for the reaction, shows an acceptable correlation between experimental and predicted reaction rates. Finally, the activation energy of RWGS over shredded steel wool was determined to be $44.4 \mathrm{~kJ} / \mathrm{mol}$. No literature values for RWGS activation energy could be found for steel wool (Fe) catalysts. However, Spencer reports RWGS activation energies over iron silicates and iron oxides ranging from $67-87 \mathrm{~kJ} / \mathrm{mol}$ over similar temperature ranges. ${ }^{4}$ It has been reported by Sacco that oxides of iron are less catalytic toward the RWGS reaction than iron or iron-carbides, thus suggesting the value determined in this work to be reasonable. ${ }^{31}$

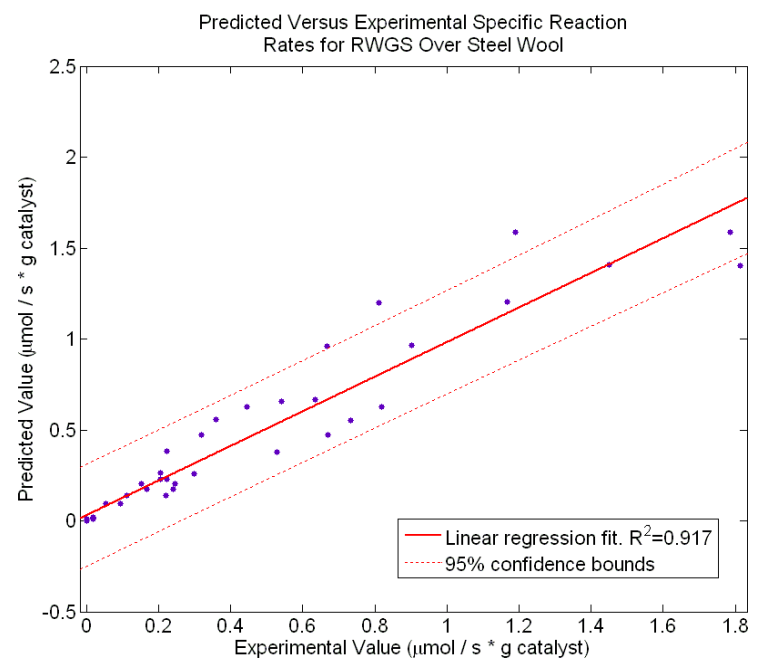

Figure 15. Predicted versus Experimental Reaction Rates for RWGS on Shredded Steel Wool. Plot indicates a good correlation between the experimental and predicted specific reaction rates.

\section{b. RWGS over Nickel Foam}

Nickel foam was shown to be active at catalyzing the RWGS reaction at temperatures of $300^{\circ} \mathrm{C}$ and above, as shown in Figure 16 and Figure 17. Values of 0.56 and 0.37 were calculated for $\alpha$ and $\beta$, respectively.

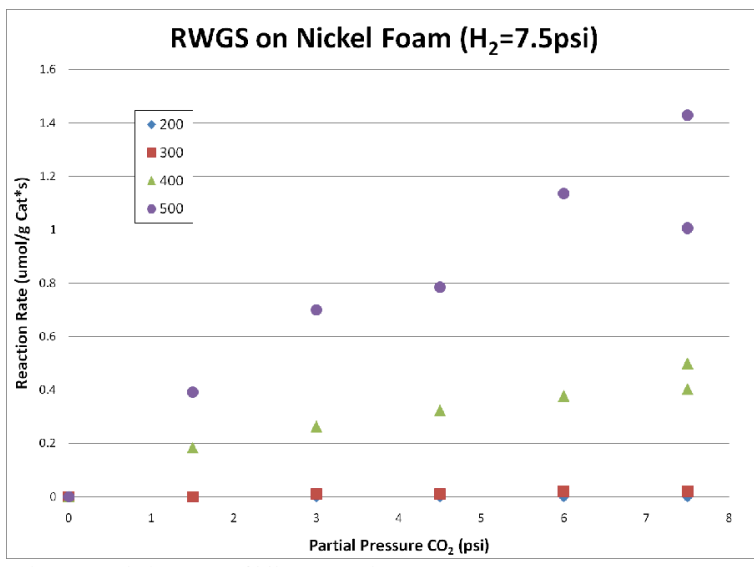

Figure 16. RWGS on Nickel Foam (constant $\mathbf{H}_{2}$ ). Reaction rate versus the partial pressure of $\mathrm{CO}_{2}$ is shown with $\mathrm{H}_{2}$ partial pressure at a constant $7.5 \mathrm{psi}$. 


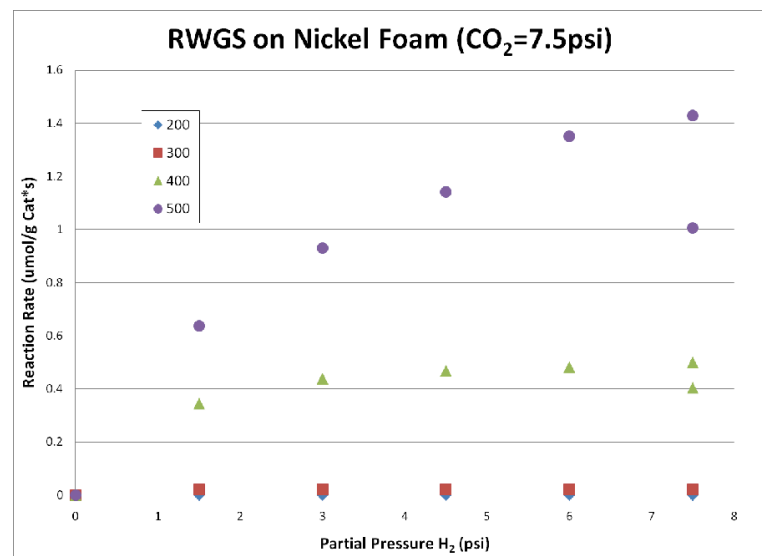

Figure 17. RWGS on Nickel Foam (constant $\left.\mathrm{CO}_{2}\right)$. Reaction rate versus the partial pressure of $\mathrm{H}_{2}$ is shown with $\mathrm{CO}_{2}$ partial pressure at a constant 7.5psi

Figure 18 shows a good correlation between experimental and predicted reaction rates using these values.

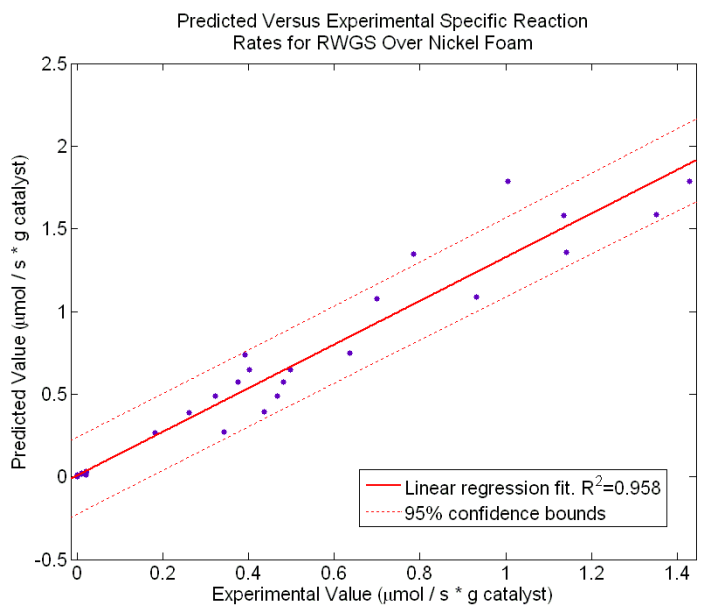

Figure 18. Predicted versus Experimental Reaction Rates for RWGS on Nickel Foam. Plot indicates a good correlation between the experimental and predicted specific reaction rates.

The activation energy for RWGS over nickel foam was determined to be $75.6 \mathrm{~kJ} / \mathrm{mol}$. This value is in the same range as palladium, copper, and zincoxide catalysts as reported by Spencer. ${ }^{4}$ While this value for activation energy would imply that the nickel foam was not as effective at catalyzing the RWGS reaction as the shredded steel wool (44 $\mathrm{kJ} / \mathrm{mol}$ ), the data in Figure 19 and Figure 20 show that at $500^{\circ} \mathrm{C}$ the nickel foam resulted in significantly higher reaction rates when the feed was $\mathrm{CO}_{2}$-rich. This indicates a greater dependence on hydrogen in the system for shredded steel wool as suggested by the differences in $\beta$ values.

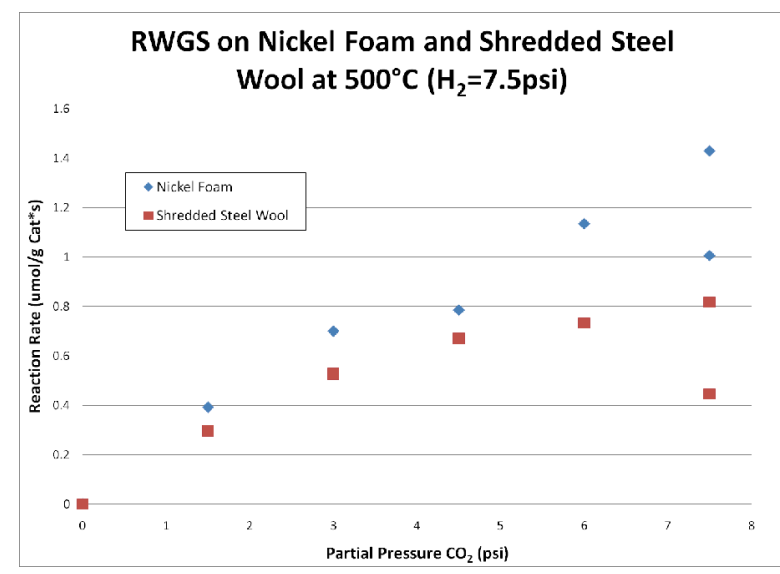

Figure 19. Comparison of RWGS Reaction Rates for Nickel Foam and Shredded Steel Wool (constant $\left.\mathbf{H}_{2}\right)$. Reaction rates versus the partial pressures of $\mathrm{CO}_{2}$ are shown with $\mathrm{H}_{2}$ partial pressure at a constant 7.5 psi.

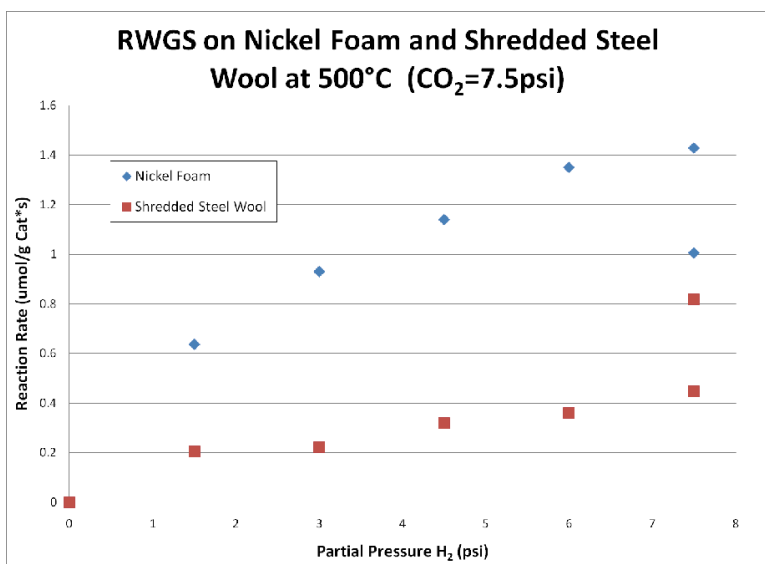

Figure 20. Comparison of RWGS Reaction Rates for Nickel Foam and Shredded Steel Wool (constant $\mathbf{C O}_{2}$ ). Reaction rates versus the partial pressures of $\mathrm{H}_{2}$ are shown with $\mathrm{CO}_{2}$ partial pressures at a constant 7.5 psi.

c. RWGS over Aluminum-Supported Cobalt

Aluminum-supported cobalt was shown to be active at catalyzing the RWGS reaction at $500^{\circ} \mathrm{C}$. Although lower temperatures were explored $\left(200^{\circ} \mathrm{C}\right.$, $300^{\circ} \mathrm{C}$, and $400^{\circ} \mathrm{C}$ ), no reaction was observed as seen in Figure 21 and Figure 22. With data available at only one temperature, activation energy for the RWGS over this catalyst could not be determined. Also, resulting $\alpha$ and $\beta$ values are not reliable and are not reported herein. 


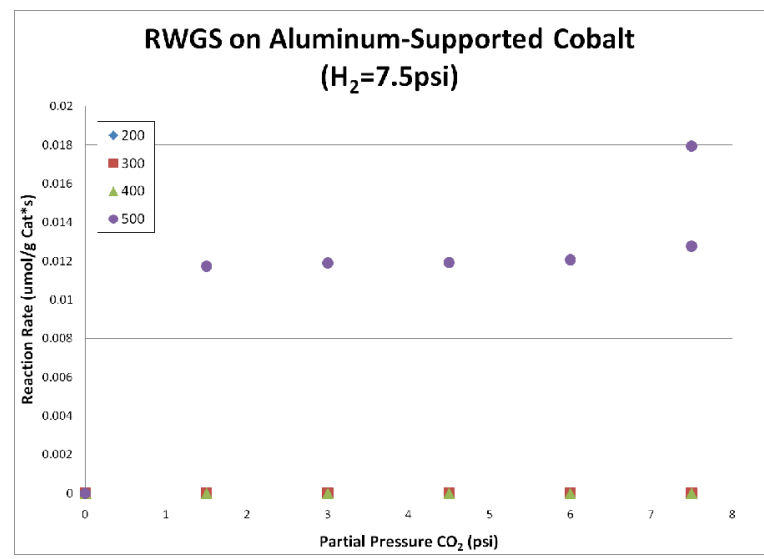

Figure 21. RWGS on Aluminum-Supported Cobalt (constant $\mathbf{H}_{2}$ ). Reaction rate versus the partial pressure of $\mathrm{CO}_{2}$ is shown with $\mathrm{H}_{2}$ partial pressure at a constant $7.5 \mathrm{psi}$.

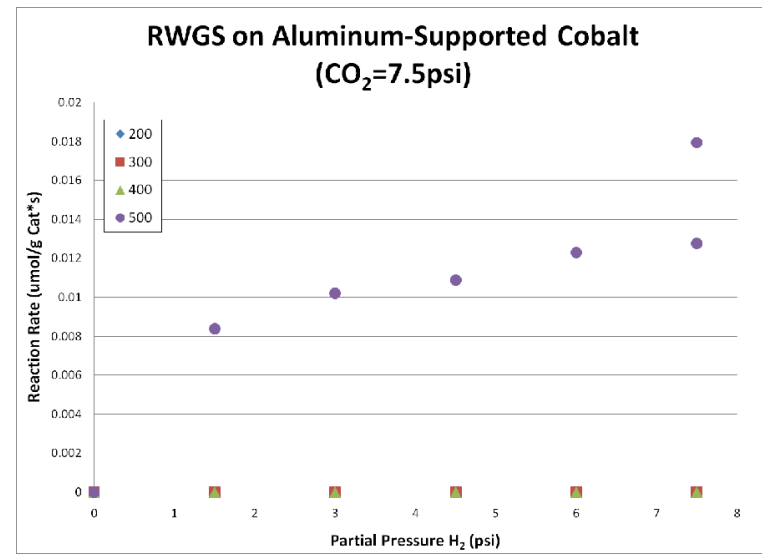

Figure 22. RWGS on Aluminum-Supported Cobalt (constant $\mathrm{CO}_{2}$ ). Reaction rate versus the partial pressure of $\mathrm{H}_{2}$ is shown with $\mathrm{CO}_{2}$ partial pressure at a constant $7.5 \mathrm{psi}$

\section{d. RWGS over Nickel Wool}

Nickel wool was shown to be active at catalyzing the RWGS reaction at temperatures of $450^{\circ} \mathrm{C}$ and $600^{\circ} \mathrm{C}$ as seen in Figure 23 and Figure 24. From the data, values of 0.75 and 0.42 were calculated for $\alpha$ and $\beta$, respectively. As seen in the predicted versus experimental plot in Figure 25, these values seem reliable.

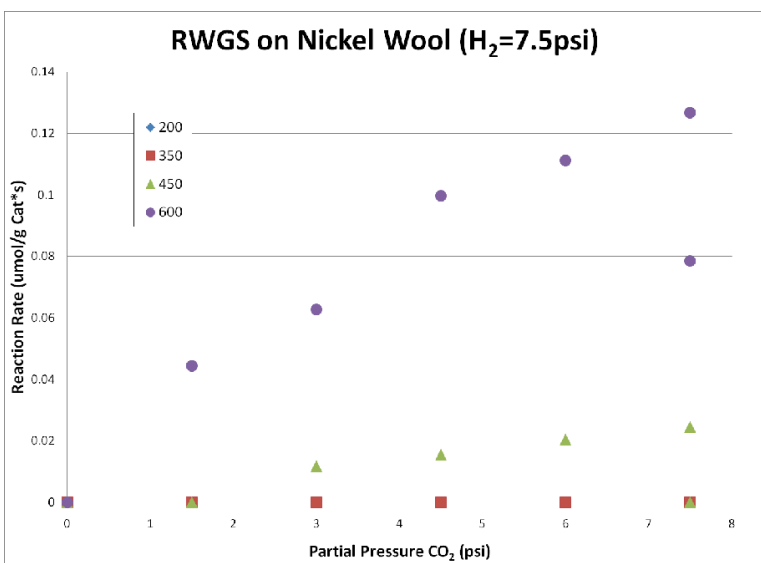

Figure 23. RWGS on Nickel Wool (constant $\mathbf{H}_{\mathbf{2}}$ ). Reaction rate versus the partial pressure of $\mathrm{CO}_{2}$ is shown with $\mathrm{H}_{2}$ partial pressure at a constant $7.5 \mathrm{psi}$.

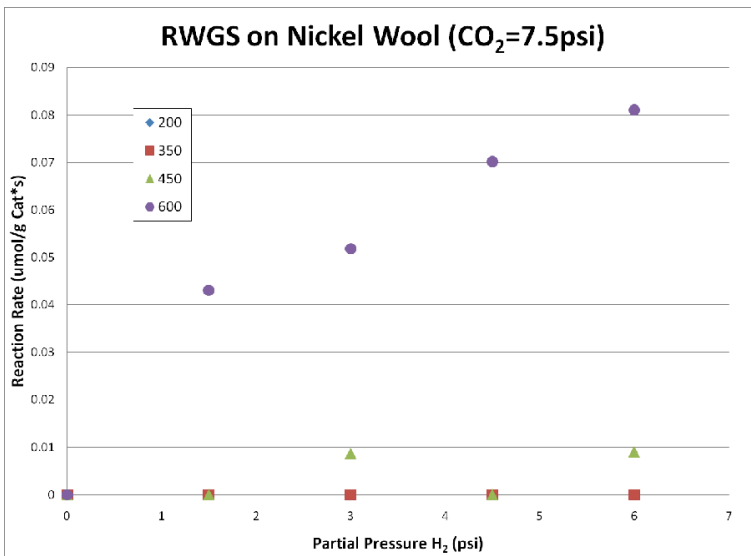

Figure 24. RWGS on Nickel Wool (constant $\mathrm{CO}_{2}$ ). Reaction rate versus the partial pressure of $\mathrm{H}_{2}$ is shown with $\mathrm{CO}_{2}$ partial pressure at a constant 7.5psi

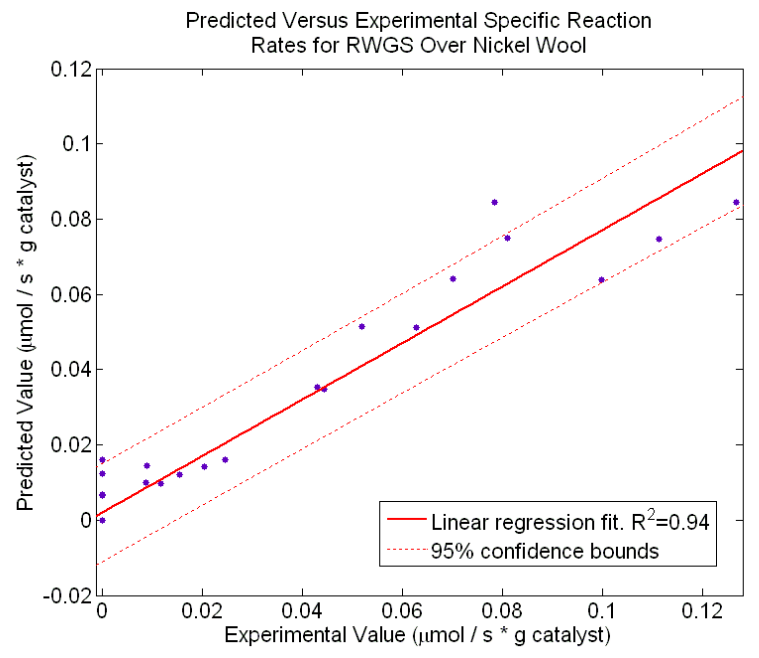

Figure 25. Predicted versus Experimental Reaction Rates for RWGS on Nickel Wool. Plot indicates a good correlation between the experimental and predicted specific reaction rates.

14

American Institute of Aeronautics and Astronautics 


\section{Hydrogenation Reaction}

Hydrogenation of $\mathrm{CO}$ has been extensively studied in the literature. However, these studies have focused almost exclusively on the formation of hydrocarbons via the Fischer-Tropsch Process as shown in equation 6.

$$
\mathrm{nCO}+(2 \mathrm{n}+1) \mathrm{H}_{2} \rightarrow \mathrm{C}_{\mathrm{n}} \mathrm{H}_{(2 \mathrm{n}+2)}+\mathrm{nH}_{2} \mathrm{O}
$$

For this study, Hydrogenation of $\mathrm{CO}$ to form water and solid carbon, as seen in equation 3, was of most interest. Although this reaction has not been as extensively studied in the literature, two rate equations have been proposed to describe the hydrogenation of $\mathrm{CO}$ to form solid carbon. ${ }^{35}$ Both rate equations, seen below, are derived from a mechanism that first involves the dissociative adsorption of $\mathrm{CO}$ and $\mathrm{H}_{2}$ on the catalyst surface.

$$
\begin{gathered}
r_{c}=k_{7} P_{C O}^{a} P_{H_{2}}^{b} \\
r_{c}=k_{8}\left(P_{C O} P_{H_{2}}\right)^{h}
\end{gathered}
$$

Adsorbed hydrogen atoms react with an adsorbed oxygen atom to form water, which is then desorbed. Carbon remains on the surface, but ultimately migrates to areas of dislocation where they form either free carbon or iron carbides. ${ }^{36}$ It should be noted that due to the feed stream reactants, both the Boudouard and Sabatier reactions had the potential to occur on each catalyst during testing. Both reactions are addressed in later sections.

Each test catalyst was presented with $\mathrm{CO}$ and $\mathrm{H}_{2}$ for the purpose of Hydrogenation testing. Of these, only aluminum-supported nickel and aluminum-supported cobalt showed no reactivity. Nickel foam and nickel wool both showed carbon formation through the hydrogenation reaction. However, due to the limited availability of data, values for constants could not be determined. Only the hydrogenation reaction over shredded steel wool provided sufficient data for an analysis using equations 7 and 8 . The rates of the hydrogenation reaction and partial pressures of feed $\mathrm{H}_{2}$ and $\mathrm{CO}$ were used to evaluate $\mathrm{a}, \mathrm{b}, \mathrm{h}$, and the activation energies from $\mathrm{k}_{7}$ and $\mathrm{k}_{8}$ as described in equations 7 and 8 above. Table 5 shows the values determined from the data.

Table 5. Calculated Hydrogenation Rate Equation Constants. Values determined from experimental data. Activation energies for equations 7 and 8 are noted with subscripts.

\begin{tabular}{|c|c|}
\hline \multicolumn{2}{|c|}{$\begin{array}{c}\text { Calculated } \\
\text { Hydrogenation } \\
\text { Constants }\end{array}$} \\
\hline $\mathrm{a}$ & 1.07 \\
\hline $\mathrm{b}$ & -0.79 \\
\hline $\mathrm{h}$ & 0.57 \\
\hline $\mathrm{E}_{7}$ & $39.3 \mathrm{~kJ} / \mathrm{mol}$ \\
\hline $\mathrm{E}_{8}$ & $44.2 \mathrm{~kJ} / \mathrm{mol}$ \\
\hline
\end{tabular}

It is clear from the value of "b" that equation 7 is inadequate at describing the hydrogenation reaction on shredded steel wool. A negative value would place the partial pressure of $\mathrm{H}_{2}$ in the denominator, which would not fit the proposed mechanism of the reaction. Additionally, the value of " $h$ " determined in this analysis closely matches the values reported by Manning $(0.42+0.10)$ and Everett $(0.50)$ over steel wool catalysts. ${ }^{35,37}$ However, the activation energy determined from equation 8 was slightly lower than that reported by Manning $(70 \mathrm{~kJ} / \mathrm{mol})$. It can be seen

from Figure 26 that the experimental data do not closely match the predicted values from equation 8 . This can be directly attributed to inadequate $\mathrm{k}$ values. More testing will be required to determine more accurate $\mathrm{k}$ values and the corresponding activation energy.

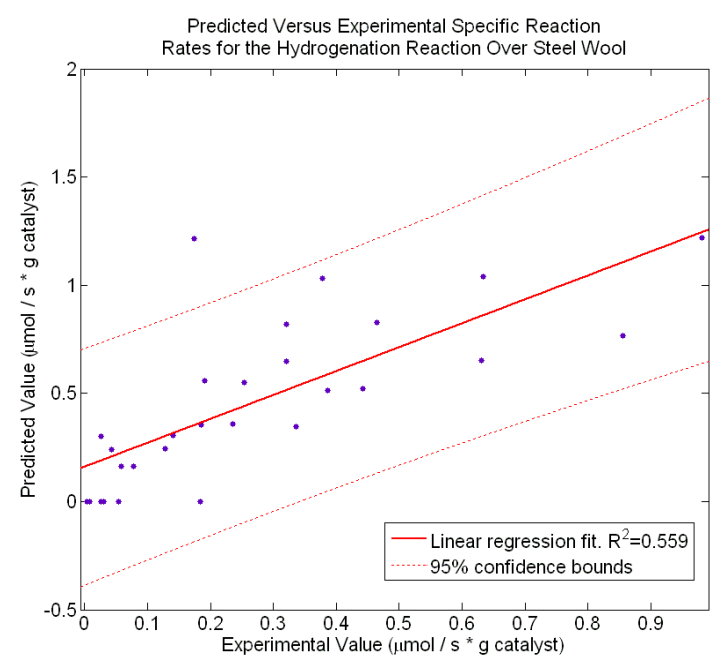

Figure 26. Predicted versus Experimental Reaction Rates for Hydrogenation on Shredded Steel Wool. Plot indicates a poor correlation between the experimental and predicted specific reaction rates.

American Institute of Aeronautics and Astronautics 


\section{Boudouard Reaction}

Boudouard data was collected for all catalysts in this study and was shown to occur while conducting testing with only $\mathrm{CO}$ as a reactant in the feed stream, and while conducting testing with both $\mathrm{CO}$ and hydrogen as reactants in the feed stream. Boudouard reaction models and the Boudouard reaction with $\mathrm{CO}$ and $\mathrm{CO} / \mathrm{H}_{2}$ feed streams are discussed below.

\section{a. Boudouard Models}

In the Boudouard reaction, carbon monoxide reacts to form carbon dioxide and solid carbon as seen previously in equation 4. Three kinetic models have been proposed and discussed at length in the literature to explain this reaction over various catalysts and at various temperatures and pressures. ${ }^{17,18,22,32}$ Each of the models is briefly described below.

\section{Boudouard Model 1}

For Model 1, the first step in the Boudouard reaction is the adsorption of $\mathrm{CO}$ on a surface. The surface-bound $\mathrm{CO}$ dissociates to form $\mathrm{C}$ and $\mathrm{O}$ at separate surface sites. Finally, the surface oxygen is reduced with gas phase $\mathrm{CO}$ to form $\mathrm{CO}_{2}$. Tottrup ${ }^{17}$ assumed the dissociation of $\mathrm{CO}$ as the rate-limiting step resulting in the rate expression:

$$
r_{c}=k \frac{P_{C O}}{\left[1+K_{A} P_{C O}+K_{B}\left(\frac{P_{C O_{2}}}{P_{C O}}\right)\right]^{2}}
$$

Boudouard Model 2

For Model 2, the first step in the Boudouard reaction is the adsorption of $\mathrm{CO}$ on a surface. Two surface-bound $\mathrm{CO}$ molecules react to form $\mathrm{CO}_{2}$ and $\mathrm{C}$ on separate surface sites. Finally, $\mathrm{CO}_{2}$ desorbs from the surface. This model assumes that the surface reaction between the two $\mathrm{CO}$ molecules is the rate-limiting step and results in the rate expression:

$$
r_{c}=k \frac{P_{C O}^{2}}{\left[1+K_{A} P_{C O}\right]^{2}}
$$

\section{Boudouard Model 3}

Like Models 1 and 2, the first step in the Boudouard reaction for Model 3 is the adsorption of $\mathrm{CO}$ on a surface. However, for Model 3, gas phase $\mathrm{CO}$ then reacts with surface-bound $\mathrm{CO}$ to form $\mathrm{CO}_{2}$ and solid $\mathrm{C}$. With the reaction again taken to be the limiting step, this model results in an identical rate expression as that of Model 2.

Although three models are proposed for the Boudouard reaction, no differentiation can be made between Models 2 and 3 due to the identical rate expressions. Thus, for the purpose of this discussion, fits are referred to as either Model 1 or Model 2. However, it should be understood that Model 2 may indicate the mechanism of either Model 2 or Model 3. 
b. Boudouard Reaction in the Absence of Hydrogen

Among the five catalysts tested, neither the aluminum-supported nickel nor the aluminumsupported cobalt showed any catalytic activity for the Boudouard reaction in the absence of hydrogen at the temperatures tested. The nickel foam and nickel wool showed slight activity at the highest temperatures tested. However, it was determined that the limited data collected was insufficient to allow evaluation of a rate expression or rate constants for these two catalysts. Thus, only the shredded steel wool data was analyzed against the proposed Boudouard models.

The reaction rates of the Boudouard reaction at multiple temperatures over shredded steel wool are shown in Figure 27 as a function of $\mathrm{CO}$ partial pressure.

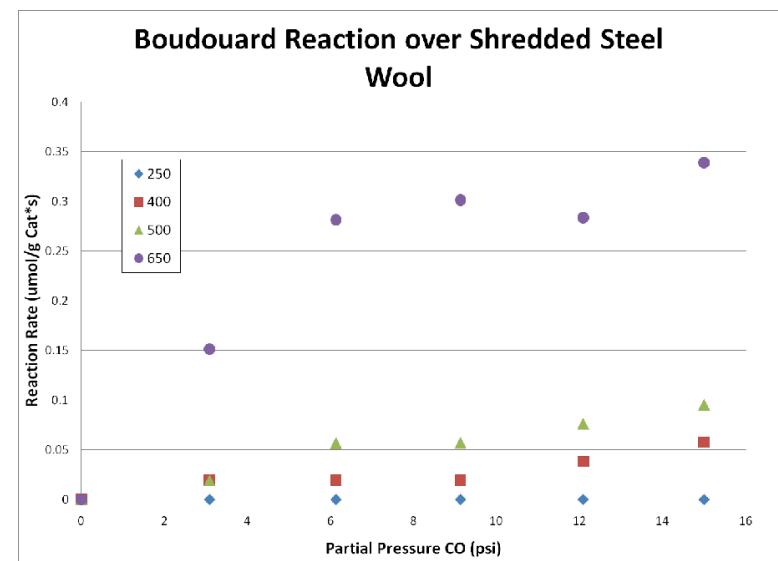

Figure 27. Boudouard Reaction over Shredded Steel Wool. Reaction rates are shown as a function of CO partial pressure.

In testing described in this paper, no $\mathrm{CO}_{2}$ was fed to the system for Boudouard trials. Thus, Model 1 can be rewritten as shown in equation 11 .

$$
\sqrt{\frac{P_{C O}}{r_{c}}}=\frac{1}{\sqrt{k}}+\frac{K_{A}}{\sqrt{k}} P_{C O}
$$

Values for $\mathrm{k}$ and $\mathrm{K}_{\mathrm{A}}$ can be determined by plotting the left side of the equation versus the partial pressure of CO. Figure 28 shows the data fitted to Models 1 and 2. It is clear from the $\mathrm{R}^{2}$ values that both models accurately predict the reaction rates based on the partial pressure of CO. Because neither model is obviously better than the other, no conclusions can be drawn with respect to the mechanism of the Boudouard reaction on shredded steel wool. Additional studies with $\mathrm{CO}_{2}$ in the feed stream may help differentiate between the two models.

by the presence of hydrogen for shredded steel wool and nickel foam. The hydrogenation reaction

appeared to account for only a portion of the increased rate of consumption of carbon monoxide, confirming hydrogen as a facilitator for the Boudouard reaction as proposed by Geurts et al., most likely through inhibition of catalyst oxide formation. ${ }^{32}$ As with the Boudouard reaction in the absence of $\mathrm{H}_{2}$ discussed above, no Boudouard reaction was observed for aluminum-supported nickel or aluminum-supported cobalt when presented with a $\mathrm{CO} / \mathrm{H}_{2}$ feed stream. Very small quantities of carbon dioxide were observed during the testing of the nickel wool, indicating that the Boudouard reaction was proceeding at a slow rate. However, these values were sufficiently small to prevent any accurate conclusions. The Boudouard reaction rates in the presence and absence of hydrogen can be seen for shredded steel wool and nickel foam in Figure 29 and Figure 30 below.

c. Boudouard Reaction in the Presence of Hydrogen During testing, it was observed that the rate of the Boudouard reaction was dramatically increased 


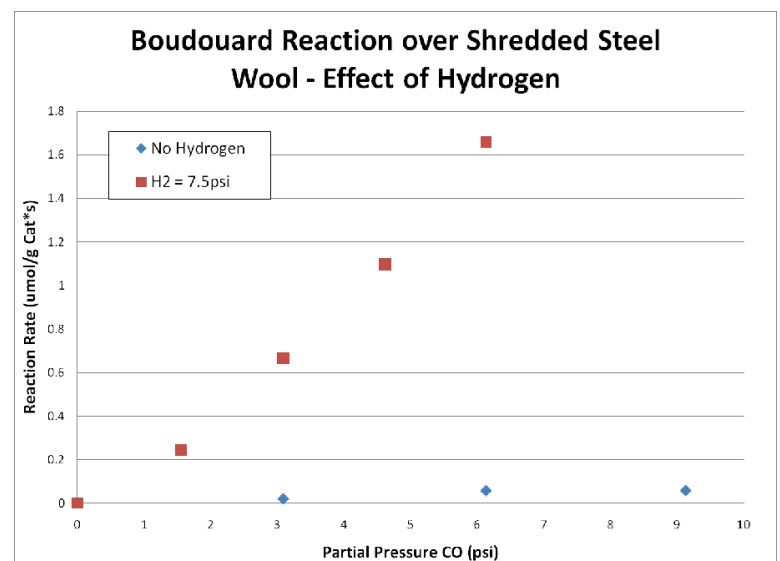

Figure 29. Boudouard Reaction over Shredded Steel Wool - Effect of Hydrogen. The reaction rates of the Boudouard reaction are shown for shredded steel wool in the presence and absence of hydrogen in the feed stream.

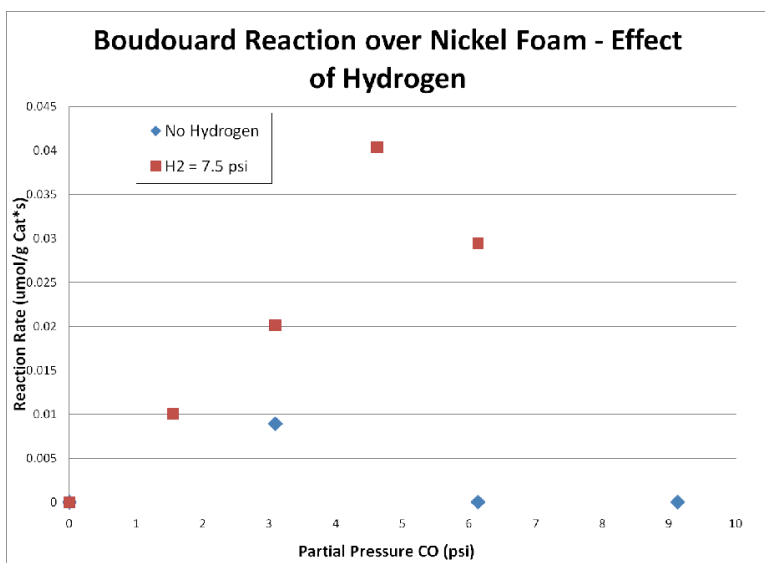

Figure 30. Boudouard Reaction over Nickel Foam - Effect of Hydrogen. The reaction rates of the Boudouard reaction are shown for shredded steel wool in the presence and absence of hydrogen in the feed stream.

\section{Sabatier Side-Reactions}

Methane and water can be formed from either $\mathrm{CO}_{2}$ or $\mathrm{CO}$ via the Sabatier reaction as seen in equations 12 and 13 , respectively.

$$
\begin{gathered}
\mathrm{CO}_{2}+4 \mathrm{H}_{2} \rightarrow \mathrm{CH}_{4}+2 \mathrm{H}_{2} \mathrm{O} \\
\mathrm{CO}+3 \mathrm{H}_{2} \rightarrow \mathrm{CH}_{4}+\mathrm{H}_{2} \mathrm{O}
\end{gathered}
$$

The presence of $\mathrm{CO}_{2}$ and $\mathrm{H}_{2}$ in RWGS testing and the presence of $\mathrm{CO}$ and $\mathrm{H}_{2}$ in Hydrogenation testing allow for potential methane formation. Of the catalysts tested, only the shredded steel wool and the nickel foam showed any methane in the product streams. However, methane was only observed in Hydrogenation testing for shredded steel wool, and only in RWGS testing for nickel foam. This indicates different reaction pathways for the Sabatier reaction on each catalyst. This knowledge will be critical in choosing catalysts for a series-type Bosch reactor system where the catalysts will be tuned to specific reactions. From this data, production of the undesired methane product must be taken into account for nickel foam as a RWGS catalyst and shredded steel wool as a Hydrogenation catalyst.

\section{Future Testing}

Future testing for Bosch and Bosch systems will include additional catalyst testing, H-Bosch reactor development, investigation of alternative process configurations, and potential regenerative catalytic reactors. Each is discussed below.

\section{Ongoing B-CaTS Alternative Catalyst Testing}

Catalyst testing in the BCaTS is scheduled to continue through May 2010. The same trial series conducted for each of the catalyst candidates discussed in this report will be repeated using a second nickel foam of the same composition as the first but with a larger pore size, the wound steel wool tested in the H-Bosch, a second nickel wool with significantly larger surface area than the currently tested nickel wool, nickel and cobalt particulates generated from rods of the pure metals, and nickel plated on a copper support of the same geometry as the aluminum supports used in this testing. As noted in the Results section, several of the component reactions over specific catalysts could not be effectively analyzed due to insufficient or inconclusive data. In order to obtain the data necessary for those analyses, additional trials will be amended to the test series and many trials will be repeated. In addition, a small number of more experimental tests will be conducted in order to investigate various important characteristics of the component reactions and catalysts or unusual operating conditions that are not yet well understood. These will likely include testing of a small selection of the candidate catalysts pre-seeded with product carbon, testing of quartz reactor tubes with no catalyst, testing of combination catalysts (i.e. nickel and steel wools 
intertwined or configured in series along the flow path), and testing of metallic catalysts with heat supplied via electrical resistive heating of the catalyst.

\section{Horizontal Bosch Developmental}

Demonstration-scale advanced catalyst testing in the H-Bosch will begin in July 2010. This test series will utilize the nickel foam and nickel wool, as each demonstrated suitably high catalytic activity for RWGS and at least one of the carbon deposition reactions. Time and resources permitting, the steel wool catalysts may be retested in order to confirm the repeatability of prior results. Additional catalysts may be included based on results of the continuing B-CaTS investigations. Furthermore, observations made from the experimental B-CaTS tests may lead to tests in this series, for example a mixed catalyst or a pre-seeded catalyst cartridge may be included.

\section{B-CaTS Alternative Process Configuration}

Following the basic advanced catalyst testing at the demonstration scale, a second tube-and-furnace reactor assembly on the B-CaTS, which is of an identical design to the first and has not been utilized for the testing reported herein, will be installed in a series configuration with the first reactor. This will allow the investigation of a system in which the first reactor is optimized for the RWGS reaction while the second is optimized for one or both of the carbon deposition reactions. Such a system has the potential for increased overall reaction rates per total catalyst mass and increased energy efficiency as a result of increased single-pass conversions (equivalently, lower recycle rates) and decreased heat requirements. Based on results of testing thus far, the most promising such setup would utilize nickel foam catalyst in the first reactor, operated at $500^{\circ} \mathrm{C}$ or higher, and steel wool in the second reactor operated at approximately $500^{\circ} \mathrm{C}$.

\section{Nickel Catalyst Regeneration}

The Mond process, based on the work of Ludwig Mond and developed into a practical small-scale industrial technique at the end of the nineteenth century, exploits the unique capacity of nickel to form the organometallic complex nickel tetracarbonyl, $\mathrm{Ni}(\mathrm{CO})_{4}$, in the low temperature range of $50-60^{\circ} \mathrm{C}^{33}$ The nickel tetracarbonyl is then heated above $180^{\circ} \mathrm{C}$, at which point it decomposes forming gaseous carbon monoxide and depositing pure nickel. A Bosch $\mathrm{CO}_{2}$ Reduction System could theoretically leverage this process to regenerate nickel catalysts and, thereby, eliminate the need for catalyst resupply which remains the most critical disadvantage of Bosch applications despite several decades of development. Such a system would require multiple reactors with one in active Bosch operation, another being stripped of its deactivated nickel, leaving the deposited carbon behind, and a third containing the bare substrate onto which the nickel is deposited.

The considerable advantages of this architecture are impaired by serious safety concerns. Among these obstacles, the most difficult to overcome is the extreme toxicity of the tetracarbonyl, which can be lethal by inhalation and even by absorption through the skin. A concentration of $30 \mathrm{ppm}$ is reportedly sufficient to cause immediate death, while the median lethal concentration $\left(\mathrm{LC}_{50}\right)$ for a 30 -minute exposure is estimated to be just 3 ppm. ${ }^{34}$ The reported level of toxicity would almost certainly necessitate exceptional safety measures, both in laboratory testing and flight application.

Notwithstanding these obstacles, it is the desire and intention of this team to investigate the potential of the Mond process for incorporation in a Bosch $\mathrm{CO}_{2}$ reduction system. Operation of a test system for this investigation is contingent upon the approval of a range of personnel and would not begin until mid- to late-2011.

\section{Conclusion}

A performance comparison between the H-Bosch tested at MSFC and a very similar system tested in 1970 confirmed the expected efficiency of the process over steel wool catalyst, as well as the challenges of carbon product containment. The maximum specific carbon formation of steel wool catalyst remains unclear, but the values reported in previous investigations were reached before any indication of catalyst deactivation occurred. A range of alternative catalysts was tested in the sub-scale B-CaTS reactor, and the results were analyzed for activity toward each of the three component Bosch reactions. The Boudouard and hydrogenation reactions were shown to proceed at higher rates over steel wool than any other catalyst tested, albeit at higher reaction temperatures. For the RWGS reaction, only nickel foam was as effective a catalyst as steel wool. Proposed rate laws for each of the component reactions were compared with the test results and coefficient values reported where sufficient data was available.

Future work will include testing of several more alternative catalysts in the B-CaTS, followed by an investigation of a series-reactor process configuration in which two reactors will be optimized for complementary component reactions. These tests will continue to focus on reducing the reaction temperature and recycle rate requirements. 
Finally, a test will be designed to evaluate the potential regeneration of nickel catalysts through the Mond process, although significant safety considerations must be taken into account prior to testing.

\section{Acknowledgments}

The authors would like to acknowledge the technical support of Tom Williams and David Long for software and hardware development of the H-Bosch and B-CaTS test stands. They acknowledge Zach Greenwood for his contributions in preparing and conducting H-Bosch testing and Tony Mahathey and Curtis Leslie in B-CaTS testing. They would also like to thank Kenny Bodkin for his support of hardware development and Gena Gibbs-Dalton and Joseph Scott for catalyst preparation.

\section{References}

${ }^{1}$ Roberts, B.C., Carrasquillo, R.L., DuBiel, M.Y., Perry, J.L., Ogle, K.Y., "Space Station Freedom Environmental Control and Life Support System Phase III Simplified Integrated Test Detailed Report," NASA Technical Memorandum-4204, 1990.

${ }^{2}$ Carrasquillo, R.L., Carter, D.L., Holder, D.W. Jr., McGriff, C.F., Ogle, K.Y., "Space Station Freedom Environmental Control and Life Support System Regenerative Subsystem Selection,” NASA Technical Memorandum-4340, 1992.

${ }^{3}$ Holmes, R.F., Keller, E.E., King, C.D., "A Carbon Dioxide Reduction Unit Using Bosch Reaction and Expendable Catalyst Cartridges," NASA Contractor Report-1682, 1970.

${ }^{4}$ Spencer, M.S., "On the Activation Energies of the Forward and Reverse Water-Gas Shift Reaction," Catalysis Letters, Vol. 32, 1995, pp. 9-13.

${ }^{5}$ Osaki, T., Narita, N., Horiuchi, T., Sugiyama, T., Masuda, H., Suzuki, K., "Kinetics of the Reverse Water Gas Shift (RWGS) Reaction on Metal Disulfide Catalysts," Journal of Molecular Catalysis A: Chemical, Vol. 125, 1997, pp. 63-71.

${ }^{6}$ Gines, M.J.L., Marchi, A.J., Apesteguia, C.R., "Kinetic Study of the Reverse Water-Gas Shift Reaction over $\mathrm{CuO} / \mathrm{ZnO} / \mathrm{Al}_{2} \mathrm{O}_{3}$ Catalysts," Applied Catalysis A: General, Vol. 154, 1997, pp. 155-171.

${ }^{7}$ Chen, C.-S., Cheng, W.-H., Lin, S.-S., "Mechanism of CO Formation in Reverse Water-Gas Shift Reaction over $\mathrm{Cu} / \mathrm{Al}_{2} \mathrm{O}_{3}$ Catalyst, " Catalysis Letters, Vol. 68, 2000, pp. 45-48.

${ }^{8}$ Park, S.-W., Joo, O.-S., Jung, K.-D., Him, H., Han, S.-H., "Development of $\mathrm{ZnO} / \mathrm{Al}_{2} \mathrm{O}_{3}$ Catalyst for Reverse Water-GasShift Reaction of CAMERE Process," Applied Catalysis A: General, Vol. 211, 2001, pp. 81-90.

${ }^{9}$ Chen, C.-S., Cheng, W.-H., "Study on the Mechanism of CO Formation in Reverse Water Gas Shift Reaction over $\mathrm{Cu}_{-} \mathrm{SiO}{ }_{2}$ Catalyst by Pulse Reaction, TPD, and TPR," Catalysis Letters, Vol. 83, No. 3-4, 2002, pp. 121-126.

${ }^{10}$ Stone, F.S., Waller, D., "Cu-ZnO and $\mathrm{Cu}-\mathrm{ZnO} / \mathrm{Al}_{2} \mathrm{O}_{3}$ Catalysts for the Reverse Water-Gas Shift Reaction. The Effect of the $\mathrm{Cu} / \mathrm{Zn}$ ratio on the Precursor Characteristics and on the Activity of the Derived Catalysts," Topics in Catalysis, Vol. 22, No. 3-4, 2003, pp. 305-318.

${ }^{11}$ Chen, C.-S., Cheng, W.-H., Lin, S.-S., "Study of Reverse Water Gas Shift Reaction by TPD, TPR and $\mathrm{CO}_{2} \mathrm{Hydrogenation}$ over Potassium-Promoted Cu/SiO ${ }_{2}$ Catalyst," Applied Catalysis A: General, Vol. 238, 2003, pp. 55-67.

${ }^{12}$ Chen, C.-S, Cheng, W.-H., Lin, S.-S., "Study of Iron-Promoted $\mathrm{Cu} / \mathrm{SiO}_{2}$ Catalyst on High Temperature Reverse Water Gas Shift Reaction," Applied Catalysis A: General, Vol. 257, 2004, pp. 97-106.

${ }^{13}$ Wang, L., Zhang, S., Liu, Y., "Reverse Water Gas Shift Reaction Over Co-Precipitated Ni-CeO $\mathrm{C}_{2}$ Catalysts," Journal of Rare Earth Metals, Vol. 26, 2008, pp. 66-70.

${ }^{14}$ Kusner, R.E., "Kinetics of the Iron Catalyzed Reverse Water Gas Shift Reaction," Case Institute of Technology PhD Dissertation, 1962.

${ }^{15}$ Gregg, S.J., Leach, H.F., "Reaction of Nickel with Carbon Monoxide at Elevated Temperatures," Journal of Catalysis, Vol. 6, 1966, pp. 308-313.

${ }^{16}$ Madden, H.H., Ertl, G., "Decomposition of Carbon Monoxide on a (110) Nickel Surface," Surface Science, Vol. 35, 1973, pp. 211-226.

${ }^{17}$ Tottrup, P.B., "Kinetics of Decomposition of Carbon Monoxide on a Supported Nickel Catalyst," Journal of Catalysis, Vol. 42, 1976, pp. 29-36.

${ }^{18}$ Rosei, R., Ciccacci, F., Memeo, R., Mariani, C., Caputi, L.S., Papagno, L., "Kinetics of Carbidic Carbon Formation from $\mathrm{CO}$ in the $10^{-6}$ Torr Range on Ni(110)," Journal of Catalysis, Vol. 83, 1983, pp. 19-24.

${ }^{19}$ Kuijpers, E.G.M., Kock, A.J.H.M., Nieuwesteeg, M.W.C.M.A., Geus, J.W., "Disproportionation of $\mathrm{CO}$ on $\mathrm{Ni} / \mathrm{SiO}{ }_{2}$ : Kinetics and Nature of the Deposited Carbon," Journal of Catalysis, Vol. 95, 1985, pp. 13-20.

${ }^{20}$ Chen, P., Zhang, H.-B., Lin, G.-D., Hong, Q., Tssai, K.R., "Growth of Carbon Nanotubes by Catalytic Decomposition of $\mathrm{CH}_{4}$ or CO on a Ni-MgO Catalyst," Carbon, Vol. 35, No. 10-11, 1997, pp. 1495-1501.

${ }^{21}$ Zielinski, J., "Interaction of Carbon Monoxide with Supported Nickel Catalysts," Journal of Molecular Catalysis, Vol. 79, 1993, pp. 187-198.

${ }^{22}$ Tavares, M.T., Alstrup, I., Bernardo, C.A., Rostrup-Bielsen, J.R., "CO Disproportionation on Silica-Supported Nickel and Nickel-Copper Catalysts," Journal of Catalysis, Vol. 147, 1994, pp. 525-534.

${ }^{23}$ Thess, A. et al., "Crystalline Ropes of Metallic Carbon Nanotubes," Science, Vol. 273, 1996, pp. 483-487. 
${ }^{24}$ Dai, H., Rinzler, A.G., Nikolaev, P., Thess, A., Colbert, D.T., Smalley, R.E., "Single-Wall Nanotubes Produced by MetalCatalyzed Disproportionation of Carbon Monoxide," Chemical Physics Letters, Vol. 260, 1996, pp. 471-475.

${ }^{25}$ Govindaraj, A., Sen, R., Santra, A.K., Nagaraju, B.V., "Carbon Structures Obtained by the Disproportionation of Carbon Monoxide over Nickel Catalysts," Materials Research Bulletin, Vol. 33, No. 4, 1998, pp. 663-667.

${ }^{26}$ Cheng, H., Reiser, D.B., Dean, S.Jr., "On the Mechanism of Energetics of the Boudouard Reaction at FeO(llll 00$)$ Surface: $2 \mathrm{CO} \rightarrow \mathrm{C}+\mathrm{CO}_{2}, "$ Catalysis Today, Vol. 50., 1999, pp. 579-588.

${ }^{27}$ Pinheiro, J.P., Gadelle, P., "Chemical State of Supported Iron-Cobalt Catalyst During CO Disproportionation I. Thermodynamic Study," Journal of Physics and Chemistry of Solids, Vol. 62, 2001, pp. 1015-1021.

${ }^{28}$ Pinheiro, J.P., Gadelle, P., Jeandey, C., Oddou, J.L., "Chemical State of Supported Iron-Cobalt Catalyst During CO Disproportionation II. Experimental Study," Journal of Physics and Chemistry of Solids, Vol. 62, 2001, pp. 1023-1037.

${ }^{29}$ Essenhigh, K.A., Utkin, Y.G., Bernard, C., Adamovich, I.V., Rich, J.W., "Gas-Phase Boudouard Disproportionation Reaction Between Highly Vibrationally Excited CO Molecules," Chemical Physics, Vol. 330, 2006, pp. 506-514.

${ }^{30}$ Serdyuchenko, A., Mintusov, E., Frederickson, K., Lempert, W.R., Rich, J.W., Adamovich, I.V., "Isotope Effect in Boudouard Disproportionation Reaction in Optically Pumped CO," Chemical Physics, Vol. 363, 2009, pp. 24-32.

${ }^{31}$ Sacco, Albert Jr., "An Investigation of the Reactions of Carbon Dioxide, Carbon Monoxide, Methane, Hydrogen, and Water Over Iron, Iron Carbides, and Iron Oxides,” Massachusetts Institute of Technology Dissertation, 1977.

${ }^{32}$ Geurts, F.W.A.H., Sacco, A. Jr., "The Relative Rates of the Boudouard Reaction and Hydrogenation of CO over Fe and Co Foils," Carbon, Vol. 30, No. 3, 1992, pp. 415-418.

${ }^{33}$ Mond, L.C., Langer, C., Quinke, F., “Action of Carbon Monoxide on Nickel,”Journal of Chemical Society, Vol. 57, 1890, pp.749-755.

${ }^{34}$ Board on Environmental Studies and Toxicology, "Nickel Carbonyl: Acute Exposure Guideline Levels," Acute Exposure Guideline Levels for Selected Airborne Chemicals, National Academies Press, Vol. 6, 2008, pp. 213-259.

${ }^{35}$ Manning, M.P., “An Investigation of the Bosch Process,” Massachusetts Institute of Technology Dissertation, 1976.

${ }^{36}$ Walker, P.L.Jr., Rakszawski, J.F., Imperial, G.R., "Carbon Formation from Carbon Monoxide-Hydrogen Mixtures over Iron Catalysts. II. Rates of Carbon Formation,” Journal of Physical Chemistry, Vol. 63, 1959, pp. 140-149.

${ }^{37}$ Everett, M.R., "The Kinetics of Carbon Deposition Reactions in High-Temperature Gas-Cooled Reactors," D.P.Report 500, Atomic Energy Establishment, Winfrith, 1967. 